Check for updates

Cite this: Mater. Adv., 2021, 2, 2457

Received 28th December 2020, Accepted 2nd March 2021

DOI: $10.1039 / \mathrm{d} 0 \mathrm{ma01019g}$

rsc.li/materials-advances

\title{
Metal-organic framework-based materials: advances, exploits, and challenges in promoting post Li-ion battery technologies
}

\author{
Anukul K. Thakur, (D) $\dagger^{\star^{a}}$ Mandira Majumder, (D) ${ }^{\mathrm{b}}$ Shashikant P. Patole, (D) *c \\ Karim Zaghib iD ${ }^{d}$ and M. V. Reddy iD ${ }^{e}$
}

\begin{abstract}
After exclusive research for three decades on metal-organic frameworks (MOFs), can there be anything unexplored, unmapped, or unexplained? Synthetic processes, fundamental characteristics, and their suitability for various applications have previously been broadly highlighted elsewhere. It is time, however, to focus on their prospect of application in the field of post-lithium batteries. Considering the perpetual rise in the demand for safer rechargeable batteries and an urgent need to refrain from Li-based batteries, which is attributed to the limited supply of lithium, a serious consideration regarding the implementation of post-lithium rechargeable batteries at a commercial level is needed. Even though post-lithium batteries seem to be an effective solution to refrain from the excessive use of a limited reserves of lithium, several concerns are still needed to be addressed before they can be recognized for practical applications. MOFs can prove to be advantageous in providing aid for the design of electrode materials with better stability and conductivity for metal-ion batteries, act as catalysts for improving the reaction kinetics in metal-air batteries, and serve as hosts for sulfur encapsulation in metal-sulfur batteries. Currently available reviews focus mainly on the use of MOFs and MOF-based materials for Li-based rechargeable batteries. This survey aims to highlight the problems and their possible solutions in cuttingedge post-lithium batteries implementing MOFs and MOF-based materials, together with highlighting the remarkable works that have been carried out to understand the various design aspects of electrode materials so as to direct future research in this regime.
\end{abstract}

\section{Introduction}

The contribution of Lithium-ion (Li-ion) battery technology to the technical development and betterment of mankind has been highly appreciated and celebrated with the award of the Nobel prize to the Li-ion battery technology developers John Goodenough, Stanley Whittingham, and Akira Yoshino in the

\footnotetext{
${ }^{a}$ Department of Advanced Components and Materials Engineering, Sunchon National University, Chonnam 57922, Republic of Korea

${ }^{b}$ Nanostructured Composite Materials Laboratory, Department of Physics, Indian Institute of Technology (Indian School of Mines) Dhanbad, Dhanbad 826004, India

${ }^{c}$ Applied Quantum Materials Laboratory (AQML), Department of Physics, Khalifa University of Science and Technology, P. O. Box 127788, Abu Dhabi, United Arab Emirates. E-mail: shashikant.patole@ku.ac.ae

${ }^{d}$ Department of Mining and Materials Engineering, McGill University, Wong Building, 3610 University Street, Montreal, QC, H3A OC5, Canada ${ }^{e}$ Centre of Excellence in Transportation Electrification and Energy Storage (CETEES), Institute of Research Hydro-Québec, 1806, Lionel-Boulet blvd., Varennes, Qc, J3X 1S1, Canada

$\dagger$ Current address: School of Chemical Engineering, Yeungnam University, Gyeongsan, Gyeongbuk 38541, Republic of Korea. E-mail: anukulphyiitd@gmail.com
}

year 2019. ${ }^{1}$ The compact structure of Li-ion batteries has contributed a lot towards revolutionizing electronic gadgets while inculcating properties such as compactness, efficiency, flexibility, mobility, and better gravimetric and volumetric capacities. ${ }^{2,3}$ Nevertheless, after four decades of intense research and advancement, Li-ion battery technology has reached saturation but the demand for higher energy density is still prevailing. ${ }^{4}$ There can be two approaches to resolve the matter: (a) to optimize the present Li-ion systems by the optimization of the cathode, ${ }^{5,6}$ anode, ${ }^{7}$ and electrolyte materials; ${ }^{1}$ (b) to employ systems with other charge storage mechanisms.

However, the continued use of lithium metal in these types of batteries is becoming a major cause of concern due to the limited availability of lithium on earth. The relative abundance of lithium in the earth's crust is only $20 \mathrm{ppm}$. The rapid expansion of Li-based batteries in various applications has made the cost of the raw materials increase steeply in the recent years. Making it even worse, lithium is unevenly distributed and mainly found in Central and South America; thus, the fabrication of Li batteries is heavily dependent on the export/import of lithium ore from these areas, further imposing 
insecurity and transportation costs on this resource. Thus, it is highly necessary to shift the focus for electrode materials from lithium to other abundantly available low-cost materials such as $\mathrm{Na}, \mathrm{K}, \mathrm{Mg}$, and $\mathrm{Al}$. Apart from their abundance, they also possess redox potentials that are low enough or even close to that of Li and a high specific capacity, in both gravimetric and volumetric terms; thus, they can provide sufficient battery output voltage/capacity, which means satisfactory energy densities for practical applications. ${ }^{8-11}$ Various materials including conducting polymers, conducting polymer-based materials, carbon materials, carbon-based materials, and metal oxides have long been used for various energy storage systems. $^{12-24}$

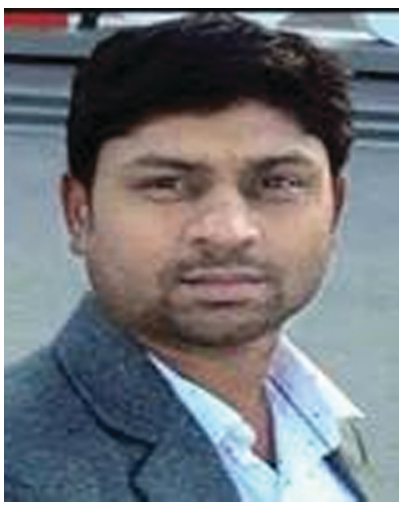

Anukul K. Thakur
Dr Anukul K. Thakur has obtained his Bachelor's and Master's degree in Physics from the University of Pune, India. He joined Indian Institute of Technology (ISM), Dhanbad, India to pursue a PhD and obtained his degree in 2018. He has experience as a postworked in $R \& D$ corporation. Currently, he is working in the Republic of Korea as a postdoctoral fellow. His research area is batteries and supercapacitor materials. His expertise lies in solid state energy storage devices and electrolytes as well as the commercial fabrication of energy storage devices. doctoral researcher. He has also
Metal-organic frameworks (MOFs) are growing as a new class of material with metal clusters embedded within organic linkers. Their segmental nature permits outstanding synthetic tunability, making it possible to achieve both fine structural as well as chemical control. Properties such as porosity, particle morphology, stability, and conductivity can be tailored for specific applications by altering the synthetic strategies for the MOFs. The demand for materials with diverse properties in rechargeable batteries makes these MOFs, with a wide range of variable properties, apt. The tunable nature of the MOFs can be effectively used to attain the requisite material properties in order to combat the persisting limitations of these rechargeable batteries. MOFs in their pristine form, in the form of

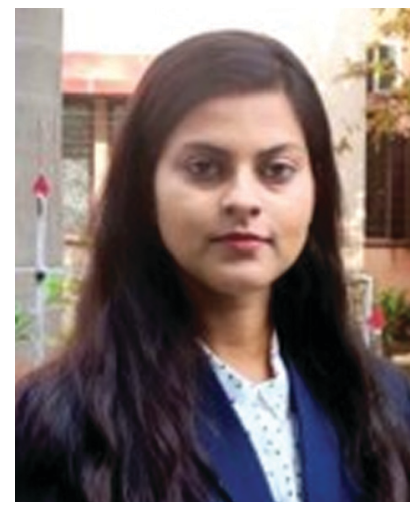

Mandira Majumder
Dr Mandira Majumder has obztained her Bachelor's degree with honors in Physics from the University of Calcutta, India. She has obtained her Master's degree in Applied Physics from Indian Institute of Technology (ISM), Dhanbad, India with distinction. She joined IIT (ISM), Dhanbad, India as a PhD researcher in the field of energy storage materials. She was awarded the Raman Charpak Fellowship and went to the University of Lille, France. Currently, her research interest includes energy storage materials, metal-organic frameworks, and polymer-based materials.

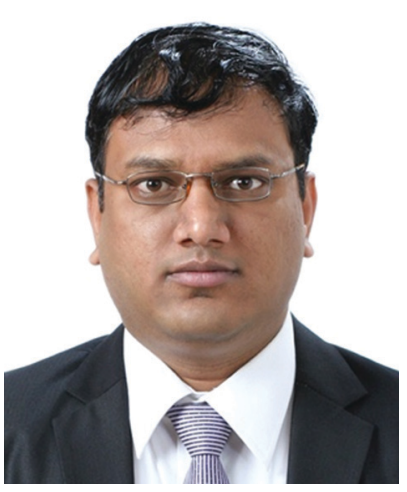

Shashikant P. Patole
Dr Shashikant Patole earned his $\mathrm{PhD}$ at Sungkyunkwan University, Suwon, South Korea in nanoscience and technology in 2010. After a first-class BSc at University of Pune, he earned his MSc in Physics, and MPhil in Physics. He is an assistant professor of Physics at Khalifa University of Science and Technology (KUST) and group leader of the "Applied Quantum Materials Laboratory". Before joining KUST, he was entrepreneur and postdoctoral researcher at King Abdulla University of Science and Technology (KAUST). There, he served as a founding member of 'Laboratory for Carbon Nanostructures' and cofounder of 'Graphene Crystal'. His research interests embrace condensed matter physics, nanoscience and technology, quantum materials, development and commercialization of advanced materials, structural composites, membranes, energy, optoelectronics, electron field emission, photovoltaics, and electron microscopy.



Karim Zaghib
Dr Zaghib holds PhD (1990) in electrochemistry from the Institut National Polytechnique de Grenoble. Later, he worked in Hydro Quebec, Canada as General Director at CETEES (2017-2020) to lead research on Li-ion batteries. Currently, he is a professor at McGill University and a strategic consultant for Investissement Québec. He has authored 420 scientific articles, edited or co-edited nearly 20 monographs, 600 patents, and 62 licences. His works have over 18181 citations and an h-index of 72. Recently, he was inducted in the top 2\% highly cited researchers in Energy. He has won many awards including 2019 Lionel-Boulet Award from the Quebec Government, Canada. 
composites, or MOF-derived materials find application in various types of rechargeable batteries including metal-ion (MI), metal-sulfur (MS), and metal-air (MA) batteries (Fig. 1). ${ }^{25-28}$ MOFs have found several applications in the field of catalysis, sensors, photovoltaics, and most importantly, energy storage (rechargeable batteries and supercapacitors) due to their high porosity, high surface area, and redox properties.

In a leap to develop high performing non-Li batteries, the implementation of MOFs and MOF derived materials as electrodes and other battery-related components is an attractive and promising option. This review will exclusively focus on various non-Li batteries including MI, MS, and MA batteries (Fig. 1). The details including the working principle and research progress made in the case of the MI, MS, and MA batteries, involving metals such as sodium, potassium, magnesium, and zinc, have been discussed in this review. A review precisely highlighting the attributes of MOF-based post-Li batteries is not available to the best of our knowledge. In this review, we have tried to outline the various aspects of post-Li MOF based batteries, the challenges faced by them, and the potential remedies adapted for implementing MOF-based electrode materials for improving their performance. The state-of-the-art of such systems has been discussed by highlighting the recent works related to the field and finally, in the conclusion, the prospects of the MOF-based post-Li batteries have been discussed.

\section{Metal-organic framework fundamentals}

MOFs, also termed porous coordination polymers, belong to a class of crystallized polymeric materials with large porosity, which are formed by the joining of metal ions/clusters centers and organic linkers (Fig. 2a). The design of coordination polymers exhibiting microporous nature such as Prussian blue started in the 18th century; however, the systematic exploration

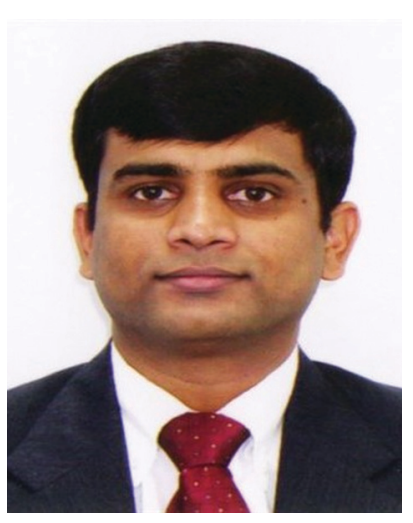

M. V. Reddy
Dr M. V. Reddy obtained his PhD (2003) with the highest honors in Materials Science from the University of Bordeaux 1, France. He worked at the National University of Singapore at the Department of Physics, Materials Science and Engineering and Chemistry as a Senior Research Fellow. He has been working at CETEES, Hydro Quebec, Canada from June 2019 on materials for energy storage: cathodes, anodes, and solid electrolytes for $\mathrm{Li} / \mathrm{Na}$ K-ion batteries and supercapacitors. He has published over 200 papers, having 15300 citations, with an h-index of 64 and is recognized in the top $2 \%$ highly cited researchers in the field of energy. He has won many awards and given 100 talks all over the world. of MOFs and their applications was initiated about two decades ago. The very first work was done by Robson, ${ }^{29,30}$ Yaghi, $^{31}$ Moore, ${ }^{32}$ and Zaworotko ${ }^{33}$ in the early 1990s. Their work and application on MOFs was further elaborated and discussed by other researchers. ${ }^{34,35}$ From then onwards, MOFs have garnered attention with the realization that these can be incorporated with appropriately modified magnetic, structural, electrical, catalytic, and optical properties by implementing appropriate metal ions and organic linkers (Fig. 2b). Since then, many synthetic strategies have been proposed for MOFs to result in various pore sizes, crystal structures, and surface chemistry. ${ }^{36}$

Unlike other porous materials including zeolites, activated carbon, and mesoporous silica, MOFs exhibit a better chemical tunability, which is attributed to their widely varying functional groups associated with the frameworks. This renders MOFs with potential for multiple applications including catalysis, sensors, energy storage, solar cell, and optoelectronic applications. Nevertheless, the instability of the functional groups associated with the ligands of MOFs severely limits the development and application of functional MOFs. For the applications including catalysis and sensing, robust MOFs are necessary, which eliminates several MOFs synthesized by the room temperature synthetic approach because of their low thermal or chemical stability. To synthesize sturdy MOFs, increased temperatures, microwave irradiations, and solvothermal reactions are often implemented to activate the coordination reactions. These type of synthetic processes, on the other hand, destroy the active functional groups associated with the ligands and limit the functionalities of the synthesized MOFs. Some alternative approaches have been proposed to refrain from these issues. The post-synthetic modification approach is one very popular strategy among the various alternative synthetic strategies proposed. By means of the chemical alterations of the organic linkers associated with the MOFs with requisite functional groups, the desired functionalities can be easily incorporated within the MOFs. Although the initial work on MOFs was carried out by chemists working in the area of coordination and solid-state/ zeolite chemistry, the recent advances in MOFs have attracted considerable attention from researchers working in the field of materials. ${ }^{37}$ MOFs are majorly known for their large porosity and widely controllable structural properties by varying the organic linkers and the metal nodes. The pore features and pore size distribution are very important attributes of any electrode material and play a vital role in imparting the desired properties to the MOF. The International Union of Pure and Applied Chemistry categorizes porous materials into three classes: microporous $(<2 \mathrm{~nm})$, mesoporous ( $>2 \mathrm{~nm}$ to $<50 \mathrm{~nm}$ ), and macroporous (>50 nm) (Fig. 2c). Microporous carbon possessing a specific surface area of $1251 \mathrm{~m}^{2} \mathrm{~g}^{-1}$ associated with a uniform pore size of $0.5 \mathrm{~nm}$ was obtained by the direct pyrolysis of $\mathrm{ZIF}-8$ ( $\mathrm{Zn}(2$ methylimidazole $)_{2}$ ) at a temperature of $930{ }^{\circ} \mathrm{C}$ by Qu et al. ${ }^{38}$

$\mathrm{Ji}$ et al. reported the synthesis of 3D micro-spherical hollow Mn-MOFs (3DMn-MOFs), exhibiting a large surface of $788.2 \mathrm{~m}^{2} \mathrm{~g}^{-1}$ and a diameter of about $2 \mu \mathrm{m} .{ }^{39}$ The sodium storage property of the $3 \mathrm{D}$ hollow porous carbon microspheres is very promising and when tested as the anode material, the 3DHPCMs exhibited 


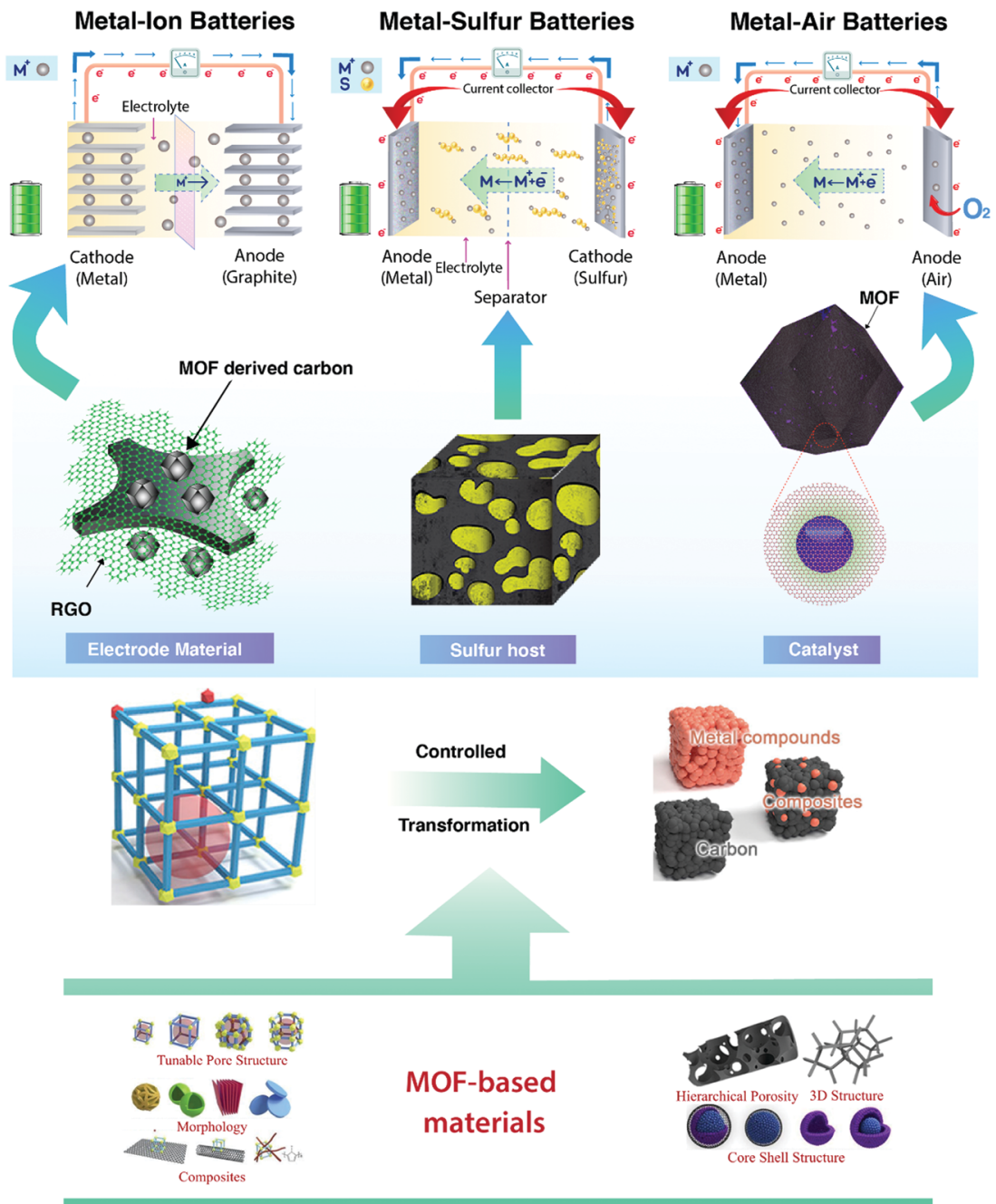

Fig. 1 MOFs in various forms for applications as catalysts, electrode materials, and sulfur hosts in various classes of rechargeable batteries. ${ }^{25-28}$ Adapted with permission from ref. 25. Copyright 2017 Royal Society of Chemistry. Adapted with permission from ref. 26. Copyright 2016 Elsevier. Adapted with permission from ref. 28. Copyright 2018 Elsevier.

excellent electrochemical storage performances, exhibiting a large specific capacity of $313.8 \mathrm{~mA} \mathrm{~h} \mathrm{~g}{ }^{-1}$ at $100 \mathrm{~mA} \mathrm{~g}^{-1} \cdot{ }^{39}$ Recently, Ingersoll et al. highlighted the comparison between the structures and performances of MOF-5- and ZIF-8-derived carbons in detail. ${ }^{40}$ They reported that initiating MOFs with bigger, more open pore structures is beneficial for augmenting the capacity and rate performance of the resulting derived carbon as a result of enhanced sodium-ion transportation and charge transfer. Furthermore, $\mathrm{ZIF}-67^{41}\left(\mathrm{Co}(2 \text {-methylimidazole })_{4}\right)$ and 1,3,5benzenetricarboxylic acid (BTC)-based $\mathrm{MOFs}^{42}$ have also shown the potential to act as precursors for the synthesis of porous carbon for sodium ion battery (SIBs). MOFs are applicable in various applications in the pristine form as and they ideally serve the purpose of acting as a precursor in designing porous carbon materials, ${ }^{43}$ metal oxide composites with carbon, and metal-based compounds. ${ }^{44}$ The exceptional porosity of MOFs is a consequence of the high length organic linkers associated with them, rendering MOFs with large storage capability and several adsorption sites. To date, $>88000$ different MOFs have been proposed and their formation is only limited by imagination. ${ }^{45}$

\section{Background and working principle}

\subsection{MI batteries}

The history and development of Li-batteries started with intercalation reaction-based Prussian-blue materials, such as iron cyanide bronzes $\mathrm{M}_{0.5} \mathrm{Fe}(\mathrm{CN})_{5}$ by Armand et al. ${ }^{45}$ Later in 1980, the group of Goodenough ${ }^{46}$ produced workable solutions by designing rechargeable 4 -volt lithium cells with lithium cobalt oxide as the positive electrode and lithium metal as the negative electrode. A decade later in 1991, Sony produced and sold the first Li-ion battery for commercial purposes. The early history of lithium battery materials is summarized in a recent review by Reddy et al. ${ }^{1}$ We will have a look at metal $(\mathrm{M}=\mathrm{Na}, \mathrm{K})$ ion batteries and their working principle, taking reference of the lithium-ion battery. For instance, a rudimentary Li-ion cell 
(a)


Metal nodes

Organic linker

Metal-Organic Framework
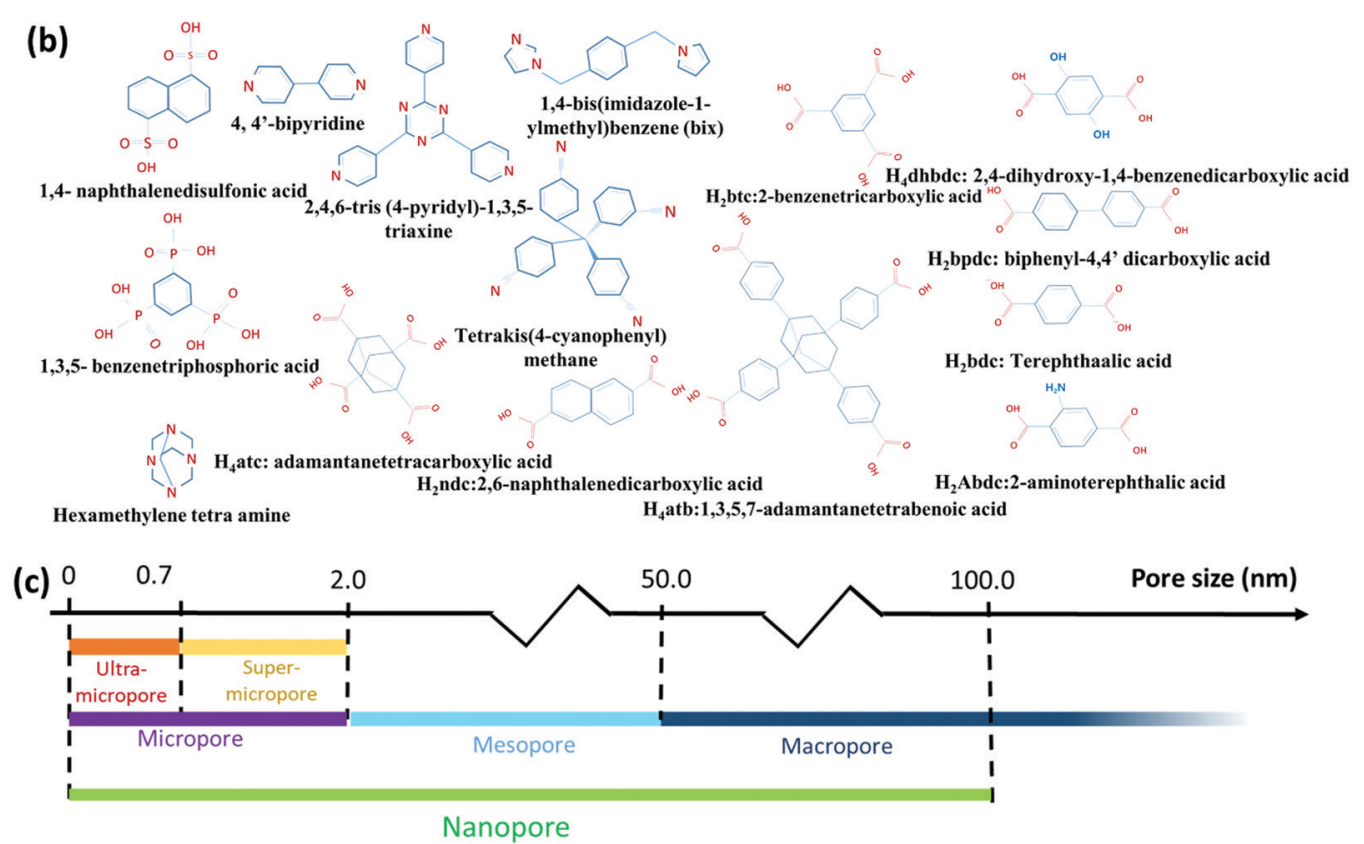

Fig. 2 (a) Structural representation of MOFs. (b) Some popularly used organic linkers for the synthesis of MOFs. (c) Schematic representation of the range of various pores found in porous materials.

comprises of an anode consisting ${ }^{47,48}$ of $\mathrm{Li}$ metal, Graphite, $\mathrm{Li}_{4} \mathrm{Ti}_{5} \mathrm{O}_{12},{ }^{49,50} \mathrm{Si}$, Sn and its carbon composites, ${ }^{51}$ a cathode consisting of $\mathrm{LiCoO}_{2}{ }^{52}$ or layered solid solutions $\mathrm{LiNi}_{x} \mathrm{Mn}_{y} \mathrm{Co}_{z} \mathrm{O}_{2},{ }^{1,53}$ $\mathrm{LiFePO}_{4},{ }^{1} \mathrm{LiMn}_{2} \mathrm{O}_{4},{ }^{1}$ or $\mathrm{K}_{2.5}\left[(\mathrm{VO})_{2}\left(\mathrm{HPO}_{4}\right)_{1.5}\left(\mathrm{PO}_{4}\right)_{0.5}\left(\mathrm{C}_{2} \mathrm{O}_{4}\right)\right]^{54}$ are kept in contact by an organic electrolyte or gel polymer solid electrolyte, ${ }^{1,52}$ and a separator consists of polypropylene polymer to electrically disconnect the electrodes but allowing the passage of Li-ions and not the electrons. MOFs or MOF-derived materials can act as both the anode and cathode in rechargeable batteries. For instance, Zeng et al., have reported the use of carbon nanosheets derived from the self-assembled Al-MOF, which exhibited $193 \mathrm{~mA} \mathrm{~h} \mathrm{~g}^{-1}$ capacity after 100 cycles when tested at $100 \mathrm{~mA} \mathrm{~g}^{-1}$ for Na-ion battery applications and at a high rate of $1000 \mathrm{~mA} \mathrm{~g}^{-1}$; the MOF-derived carbon delivered a specific capacity of $109.5 \mathrm{~mA} \mathrm{~h} \mathrm{~g}{ }^{-1}$ over 3500 cycles. $^{55}$ In their work, MOF-derived carbon materials were functionally modified with a desired structure in order to improve the charge capacity. The solvothermal method was used to induce the self-assembly of the MOF, followed by carbonization and acid treatment to remove the metal nodes from the framework. As a result, carbon nanosheets associated with 2D tunable defective sub-units were created. Notably, the carbonization temperature had a dramatic effect on the final carbon skeleton structure. Thus, optimal nanostructures were obtained by varying the carbonization temperature, imparting large specific surface area and apt pore size distribution in the carbon nanosheets. Furthermore, the tunable carbon framework structure showed efficacy in refraining from irreversible damage during the charge-discharge cycles. During the electrochemical process of charging, electrons are released at the cathode, which move through the external circuit to the anode. Li-ions also move in a similar direction internally, from the cathode to the anode, passing the separator through the electrolyte. As a result of these actions, the external energy is electrochemically stored in the battery. During discharging, electrons move from the anode to the cathode via the load connected externally and Li-ions pass from the anode to the cathode internally through the electrolyte. This entire process is known as the "shuttle chair" mechanism as the process involves the shuttling of the Li-ions between the two electrodes, as has been shown in Fig. $3 .{ }^{56}$ The reaction mechanism of Li-ion batteries is broadly classified into intercalation/de-intercalation, alloying/ de-alloying, and conversion reaction. ${ }^{7}$ Present commercial batteries use the principle of intercalation/de-intercalation reaction.

\subsection{MS batteries}

The development of MS batteries dates back to the 1960s as Herbert and Ulam patented the design for a primary battery 


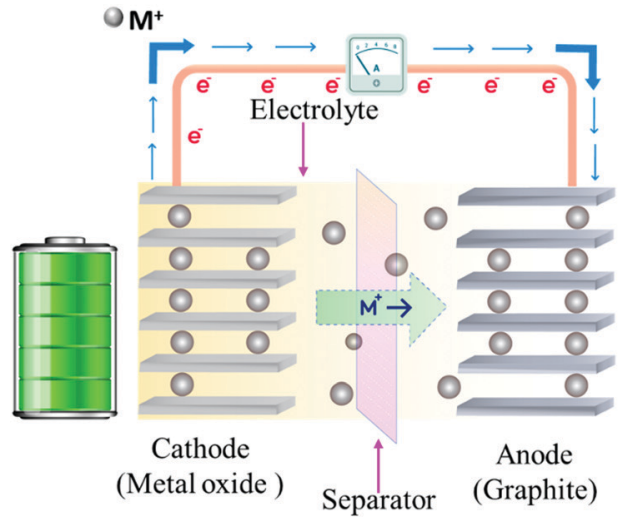

Charging

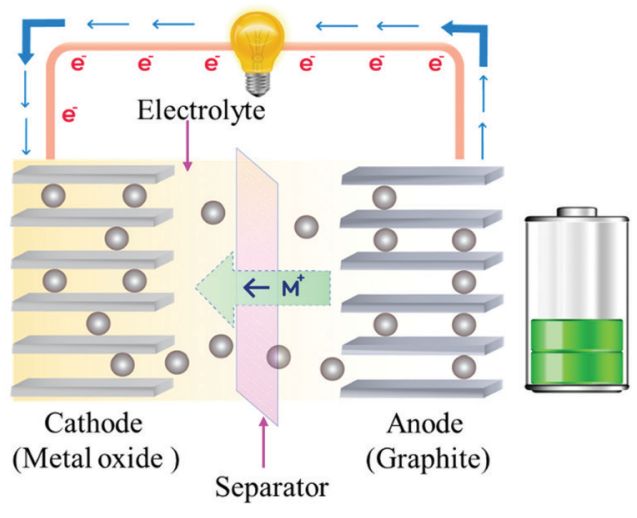

Discharging

Fig. 3 Schematic diagrams representing the charging and discharging mechanism for the metal-ion battery.

consisting of lithium-based alloys as an anode, sulfur as a cathode, and aliphatic-saturated amines as the electrolyte in the year 1962. This saw further improvement within a few years for the implementation of organic solvents as the electrolyte enhances the potential to $2.35-2.5 \mathrm{~V}$. For the past twenty years, MS battery technology has gained much popularity and research in this technology using various electrolytes, electrode materials, and separators, which have shown tremendous progress. The chemistry of metal-S battery will be now explained as follows, as has been shown in Fig. 4.

Interactions at the anode: the anode usually consists of the metal (M). During the charging process, a significant amount of metal from the anode dissolves into the electrolyte, generating metal ions and electrons as $2 \mathrm{M} \leftrightarrow 2 \mathrm{M}^{+}+2 \mathrm{e}^{-}$.

Interaction at the cathode: during charging, $\mathrm{M}^{+}$that dissolves from the anode travels to the sulfur cathode, where they bind with the sulfur present in the cathode, producing $\mathrm{M}_{2} \mathrm{~S}$ by following the reaction path $\mathrm{S}+2 \mathrm{M}^{+}+2 \mathrm{e}^{-} \rightarrow \mathrm{M}_{2} \mathrm{~S}$, leading to the overall cell reaction $2 \mathrm{M}+\mathrm{S} \rightarrow \mathrm{M}_{2} \mathrm{~S}$. Sulfur reduction proceeds through several intermediate steps of production of polysulphides (PS) $\left(\mathrm{M}_{2} \mathrm{~S}_{x}, 8<x<1\right)$ in order to produce the final reaction products of lithium sulfides, which is the main advantage of metal-S batteries as compared to MI batteries, wherein metal ions are intercalated in the anodes and the cathodes, and $\sim 0.5$ metal-ions can be accommodated by the host atom. This is almost four times that in the case of metal-S batteries, where each host sulfur atom can accommodate two metal ions. This results in much higher energy storage capacity for the metal-S batteries as compared to that of the MI batteries. MOF-derived carbon is very effective as a sulfur host for MS batteries. ${ }^{57}$ Conventional porous carbon materials that are used as sulfur host MOFs bind to sulfur passively. Thus, the grip of carbon materials on sulfur is not very good, leading to less sulfur loading and also the dissolution of sulfur. On the other hand, due to the presence of active metal nodes, the MOF can bind to sulfur actively, thus increasing the sulfur loading and minimizing sulfur dissolution. Several examples are available where MOF-derived carbon has been used as a sulfur host for Li-S batteries. ${ }^{58}$ However, the research in this area of non-lithium sulfur batteries is still at its infancy and needs attention to make progress in this field.

\subsection{MA batteries}

The research on MA batteries commenced much earlier than that in lithium-ion batteries. The first $\mathrm{Zn}$-air battery was designed by
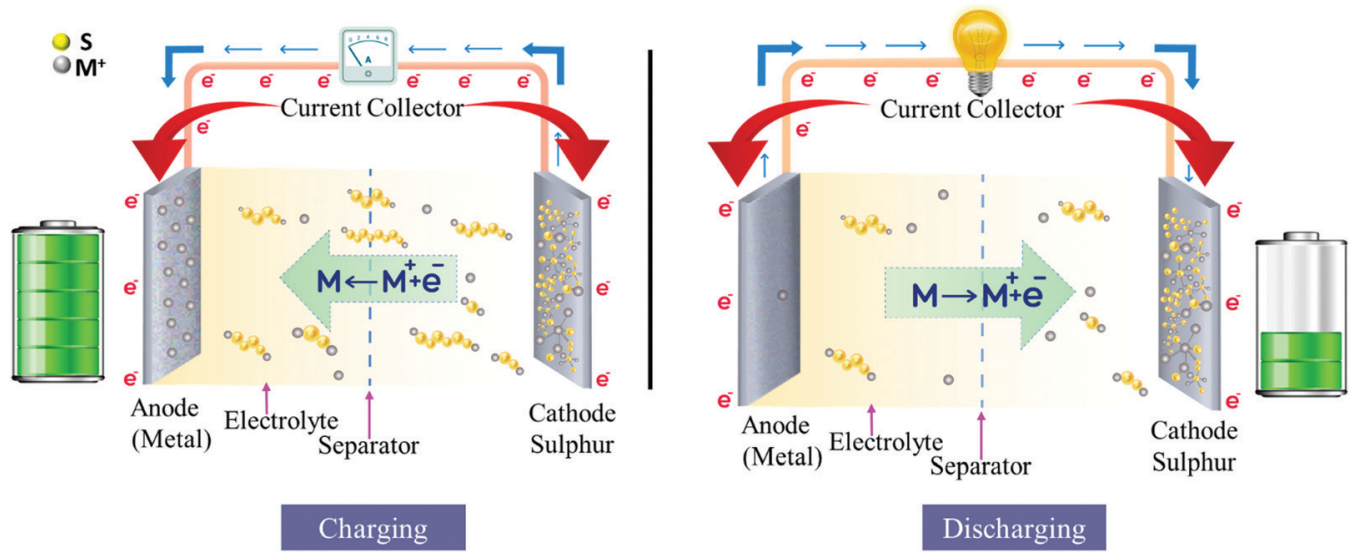

Fig. 4 Charging and discharging mechanism for an MS battery. 

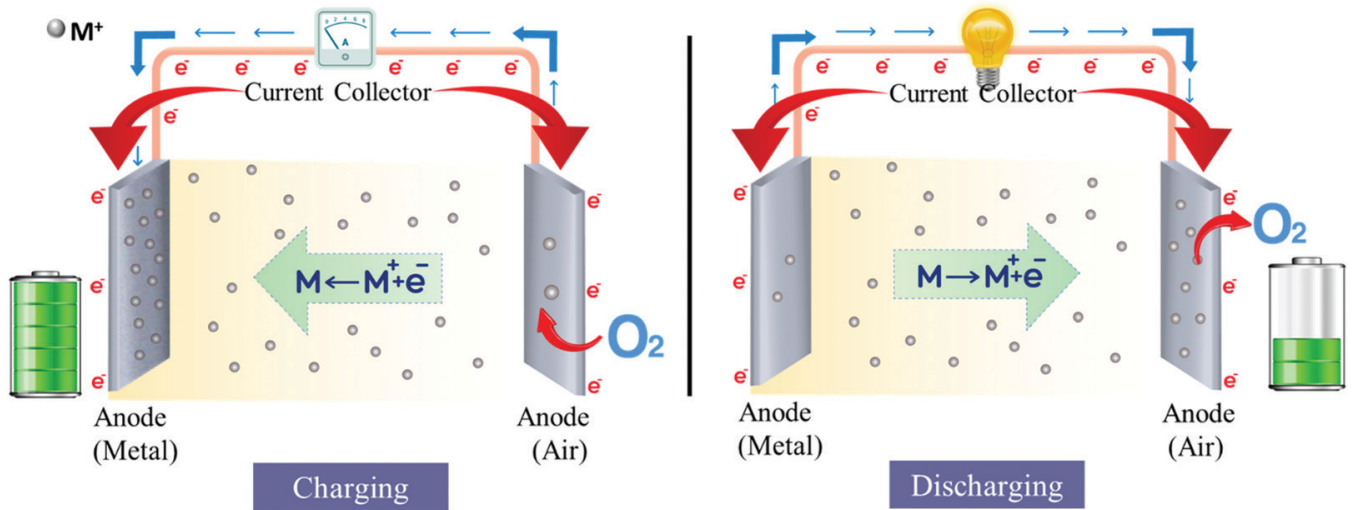

Fig. 5 Charging and discharging mechanism of an MA battery (the grey balls represents the metal deposits on the electrodes).

Maiche in 1878 and its commercial products started to enter the market in 1932. Following this, aqueous iron-air, aluminum-air, and magnesium-air batteries were developed in the 1960s. ${ }^{59}$ Aqueous MA batteries were first discovered in the 1970s as Li-air batteries implementing aqueous electrolytes were projected for the first time as a potential power storage system for electric vehicles. However, the high reactivity of the metals ( $\mathrm{Li}, \mathrm{K}, \mathrm{Na}$ ) in aqueous electrolytes raised major concerns regarding the safety and lifetime of the batteries. Only in the late 1990s, non-aqueous $\mathrm{Li}-\mathrm{O}_{2}$ batteries started to gain popularity in terms of research. The first $\mathrm{Li}-\mathrm{O}_{2}$ was developed in the year 1996 when Jiang and Abraham accidentally recognized the $\mathrm{Li}_{2} \mathrm{O}_{2}$-based $\mathrm{Li}-\mathrm{O}_{2}$ electrochemistry while attempting to intercalate Li-ions into graphite in the presence of some air leaks through a carbonate gel-polymer electrolyte. Nevertheless, due to the unwanted reactions occurring between $\mathrm{Li}$ and the electrolyte to form lithium carbonate, the design proved to be a failure with a very short life for the battery. The following years involved more research on the discharge reaction of $\mathrm{Li}-\mathrm{O}_{2}$ batteries using other electrolytes to improve the stability. In 2006, the rechargeable aspect of the $\mathrm{Li}-\mathrm{O}_{2}$ batteries first came into picture as Bruce and co-workers demonstrated the possible decomposition of $\mathrm{Li}_{2} \mathrm{O}_{2}$ on recharging, which proved to be a significant pioneering step that paved the path for reversible $\mathrm{Li}-\mathrm{O}_{2}$ batteries. MA batteries use conversion chemistry similar to MS batteries. The basic design of an MA battery (Fig. 5) consists of a metal (or metal alloy) anode, an air-rich cathode, and a saline electrolyte. The reactions involved in MA batteries are as follows, as shown in Fig. 5.

$$
\begin{gathered}
\text { Anode: } 4 \mathrm{M} \rightarrow 4 \mathrm{M}^{x+}+4 x \mathrm{e}^{-} ; \\
\text {Cathode: } x \mathrm{O}_{2}+2 x \mathrm{H}_{2} \mathrm{O}+4 x \mathrm{e}^{-} \rightarrow 4 x \mathrm{OH}^{-} ; \\
\text {Total: } 4 \mathrm{M}+x \mathrm{O}_{2}+2 x \mathrm{H}_{2} \mathrm{O} \rightarrow 4 \mathrm{M}(\mathrm{OH})_{x}
\end{gathered}
$$

where $x$ represents the valence state of the concerned metal. During the discharge process, the metal is oxidized at the anode to the metal ion, creating electrons that traverse through an external circuit through the load to perform "work". Synchronously, at the cathode, $\mathrm{O}_{2}$ passes through the air-rich cathode and is then reduced to hydroxide ions by reaction with $\mathrm{H}_{2} \mathrm{O}$ and electrons. Charging occurs in exactly the opposite way as in the case of discharging. Metals such as $\mathrm{Mg}, \mathrm{Li}, \mathrm{Al}, \mathrm{Ca}, \mathrm{Zn}$, and $\mathrm{Na}$ are widely used as electrode materials for MA batteries. The electrolyte can be both aqueous or non-aqueous, having its advantages and disadvantages. Uncontrolled reactions of $\mathrm{Li}, \mathrm{Na}$, and $\mathrm{K}$ with the aqueous electrolyte projected the necessity of implementing the non-aqueous electrolyte. MOF-based materials are a promising catalyst for oxygen reduction reaction (ORR) and oxygen evolution reaction (OER) at the cathode. For instance, Liang et al. have reported the synthesis of MOF-N doped carbon nanotubes (MOFNCNTs) by the direct pyrolysis of polyhedral ZIF-67 particles for use as a bifunctional catalyst for Na-air battery. ${ }^{60}$ The synthesized MOF-NCNTs exhibited larger stability and electrocatalytic activity of ORR and OER as compared to commercial Pt/C. The battery fabricated using MOF-NCNTs exhibited a voltage gap of $0.30 \mathrm{~V}$ at $0.1 \mathrm{~mA} \mathrm{~cm}^{-2}$. The outstanding electrocatalytic activity is credited to the synergy developed between confined Co nanoparticles in CNTs and the N dopants, the hollow morphology of NCNTs, and the strong porous cage structure. The confined Co nanoparticles in the CNTs, together with the $\mathrm{N}$ dopants, induce enhanced catalytic active sites, resulting in the promotion of electron transfer for OER and ORR. The hollow framework morphology of the NCNTs improves the $\mathrm{O}_{2}$ adsorption, which is attributed to the presence of adequate structural defect sites. This kind of morphology also augments the electronic conductivity and mass transport, causing enhanced catalytic activity and stability of the catalysts. ${ }^{60}$ The large efficacy and cost-effectiveness of MOF-derived NCNTs in this work pave the path for the development of MOF-derived carbon-based bifunctional oxygen electrocatalysts for commercial applications in hybrid MA batteries.

\section{Need for non-lithium batteries}

Though modern-generation batteries involving lithium have been exclusively studied to exhibit promising results both in the case of the $\mathrm{Li}$-ion and $\mathrm{Li}-\mathrm{S}$ batteries, as can be seen in several recent works, ${ }^{60,61}$ there are some limitations regarding the direct utilization of Li metal: (a) the utilization of Li-metal as the anode material causes significant safety apprehensions die to the formation of irrepressible Li dendrites, which could 
pierce the separator and cause an internal short circuit. (b) The formation of dendrites also leads to a reduction in the Coulombic efficiency and cycling performance as a result of the presence of "unusable $\mathrm{Li}$ " in the disconnected dendrites; (c) apart from the safety concerns, the limited availability of Li-metal on Earth makes it highly expensive. Also, Li-metal ore is not evenly distributed and the procuring of the metal purely depends on imports, which further increases the cost of raw materials. Hence, to mitigate this situation, we hastily require to seek other metals that can meet the requirements. Apart from lithium, sodium, potassium, magnesium, and calcium are some of the metals that are abundantly available on Earth and can appropriately serve the purpose. MOFs in the pristine form, MOF-derived materials, or MOF-based composites are very promising electrode materials for MI, MS, and MA batteries. ${ }^{62}$ Due to their large surface area and redox-active metal nodes, these can store charge effectively. ${ }^{63}$ In the case of MS batteries, the presence of the metal nodes allows the MOF to actively bind with the sulfur and hence limits polysulfide formation. ${ }^{62}$ For MA batteries, MOFs and MOF-based materials can be used as catalysts to speed up sluggish OER and ORR reactions at the cathode, hence resulting in the better performance of the MA battery. ${ }^{60}$ The performance and the research progress concerning the post-Li batteries involving each of these metals and MOF or MOF-derived materials will be discussed briefly in the following sections.

\section{Challenges persisting associated with non-lithium MI, MS, and MA batteries}

This section focuses on the outline of the persisting concerns that limit the use of these batteries at a commercial scale. The possible solutions to these problems are also projected.

\subsection{Challenges faced by MI batteries}

We are aware of the limited supply of lithium on Earth. However, the difficulties do not end in just choosing an alternative material to Li for batteries. The major problems concerning MI batteries are discussed below.

(1) The formation of uncontrollable metal dendrite growth results in severe safety issues. During the process of charging, the plating of the metal is not uniform and grows in a random direction, forming the so-called "dendrites". This leads to a loose and mossy growth of the metal electrode. This dendrite formation is highly dangerous as this can lead to short circuits within the cell. Also, this leads to the corrosion of the cell, thus severely reducing the cycle life of the battery. MOF-based materials as electrode materials have been reported to mitigate this problem in the case of Li-storage. ${ }^{64}$ Such studies on non-Li batteries are yet unexplored.

(2) The thermodynamic instability of the metal electrodes due to their high Fermi energy level can cause irreversible and continuous reactions between the metal and the electrolyte. This leads to the generation of thick solid electrolyte interphase layers on the metal electrode surface. These layers can be several nanometers thick and hence devour the metal electrode, electrolyte, and upsurge the internal resistance, in turn shortening the cycle life. This problem has also been reported to be solved very recently using an MOF-based material as the anode for Li-storage. ${ }^{65}$ Taking from inspiration from these aforementioned works, a similar strategy can also be tried for non-Li batteries in order to mitigate these problems.

\subsection{Challenges faced by MS batteries}

Capacity dilapidation faced by the MS battery is attributed to multiple factors as discussed here: (a) The metal PS formed during discharge easily dissolves and diffuses through the electrolyte to a distance away from the cathode redox sites. These PS are the middle products of the electrochemical reduction of sulfur occurring in the organic electrolyte. The solubility of PS is better than that of sulfur and these diffuse from the cathode to the anode (and vice versa), inducing various parasitic reactions at the anode. These unwanted parasitic reactions ultimately result in the corrosion of the anode metal, reduction in the amount of active sulfur, and lowering of the coulombic efficiency of the battery system. (b) As the reduction progresses, the metal-PS precipitates create an insulating layer along with other insoluble compounds on the cathode surface, inhibiting the transport of metal ions. Further, due to the greater volume of the sulfides as compared to solid sulfur (80\% more), it augments the passivating effect. ${ }^{66}$ (c) Due to the high dissolution rate of the PS in the organic solvent, the amount of dissolved polysulfide can be alarmingly high, which also leads to an increase in the viscosity, thus reducing the overall conductivity. ${ }^{67,68}$ (d) Sulfur suffers from the problem of low electronic conductivity $\left(\sim 10^{-17} \mathrm{~S} \mathrm{~cm}^{-1}\right)$, which limits the comprehensive utilization of the active material, leading to a low specific capacity on repetitive cycling. The research to date has identified two major methods to mitigate the problem stated above: (a) physical encapsulation of sulfur to limit the direct exposure of sulfur to the electrolyte. Several reports are available that have used mesoporous and hollow carbon to encapsulate sulfur physically and the other products formed during the discharge process within the cathode as well. However, the interaction of elemental sulfur and the carbon host is only physical and hence weak, leading to imperfect confinement and leaking of some PS. (b) Combining sulfur with other materials that do not bind to it physically but actively interact with sulfur and adsorb the PS. This strategy of binding sulfur actively to a host has been reported in several works to overcome the drawbacks of the physical encapsulation of sulfur into carbon as an alternative strategy. ${ }^{67,68}$ Other approaches include the use of separators to selectively allow only metal ions to pass, thus prohibiting polysulfides from reaching the metal electrode. These problems prevent the Li-S battery technology from being universally adopted and rapidly commercialized. ${ }^{69}$

MOFs can play a very essential part as they can hold sulfur actively while taking part in metal-ion storage. Several works have reported the implementation of MOFs as sulfur hosts to mitigate polysulfide formation in rechargeable batteries. ${ }^{70,71}$ 
MOF-derived carbon is considered as a very promising material as a sulfur host. This is attributed to the fact that conventional porous carbon binds to sulfur only physically. On the other hand, MOF-derived carbon material can attach to sulfur actively due to the presence of active metal nodes. This not only prevents the formation of polysulfide but also improves the mass loading of sulfur and proves to be very efficient in enhancing the performance of MS batteries. ${ }^{72}$ In the later sections, we have discussed the recent remarkable works where MOF-derived carbon has been used as a sulfur host for non-Li MS batteries.

\subsection{Challenges faced by MA batteries}

The main perk of the MA batteries is that the active metal in the battery reacts with oxygen taken from the surrounding air, which is not required to be stored within the battery, thus decreasing the total weight and volume of the battery. Besides, much higher theoretical specific energy can be achieved than that recorded for state-of-the-art lithium-ion batteries. MA batteries with promising aspects that are currently under consideration are sodium-air, lithium-air, magnesium-air, aluminum-air, zinc-air, and iron-air batteries. However, the consequence of the strong interactions of the battery with the surroundings in the case of the MA batteries as compared to the closed batteries is yet to be understood. Some of the major concerns associated with the MA battery system that persist and need serious attention are as follows.

(a) Unstable anodes. The stability of metal anodes in aqueous electrolytes is very less, thus significantly reducing the life-time. However, the surfaces of metals such as $\mathrm{Al}, \mathrm{Zn}$, and $\mathrm{Mg}$ can be passivated by the application of passivating oxide or hydroxide layer, making them somewhat compatible with the aqueous electrolyte. Some of the metals such as $\mathrm{Na}, \mathrm{Li}$, and $\mathrm{K}$ are so reactive with commonly used aqueous electrolytes that they raise significant safety concerns and hence, are generally used with non-aqueous electrolytes. A common strategy of handling this problem is to implement an alloy of these metals as the anode, thus restraining corrosion to some extent. Reports are available wherein MOF has been used as a shield to stabilize the anode in rechargeable batteries. ${ }^{73}$

(b) Air-cathode design and catalyst. The energy density is significantly reduced as compared to the theoretical values projected in MA batteries. The cyclic stability is also limited, which is attributed to the instability of the air-cathode materials. This is mainly because of the inefficiency of the air-catalyst, bifunctional electrocatalyst, and inefficient cathode design. To overcome the sluggish reaction kinetics of the ORR, developing better air catalysts to expedite the ORR reaction is necessary. Along with this, designing a proper air cathode to enhance the triple-phase boundary is also believed to enhance the performance of the battery. Researchers are highly dedicated towards developing bifunctional electrocatalysts and efficient air-cathode designed to enhance the efficiency of MA batteries. However, the energy efficiency of the MA batteries is still not expected to go beyond $65 \%$, which hence remains a source of concern. MOFs have been exclusively used as catalysts in $\mathrm{Zn}$-air batteries. ${ }^{74}$ Many such examples are cited in the following sections.

\section{Use of MOFs in various non-lithium batteries}

In the case of the rechargeable batteries, MOF-based materials find utilization not only as electrode materials but also as sulfur hosts, as electrocatalysts, and as selective membranes for separators. ${ }^{75}$ For instance, Qiao et al. reported the use of MOF as a separator for enhancing the cycle life of $\mathrm{Li}-\mathrm{O}_{2}$ battery by diminishing the electron shuttling effect. ${ }^{76}$ MOFs have also been reported to be used as electrolytes for solid-state rechargeable lithium batteries. According to a report by Wang et al., MOF nanocrystals impregnated with an ionic liquid have been used as a solid-state electrolyte with better ionic conductivity and improved $\mathrm{Li}^{+}$transference number. ${ }^{77,78}$ The following sections discuss in brief the various MOF-based materials that have been synthesized and have been used for the design of various nonlithium batteries.

\subsection{Use of MOF in MI batteries}

6.1.1 Pristine MOFs for MI batteries. To date, several studies have focused on cathode and anode materials for MI batteries. Commercially used conventional electrode materials face complications in synthesis, inadequate energy/power density, and cyclic instability. MOFs are promising electrode materials for MI batteries due to their unique structure, large specific surface area, a wide range of pore features, large porosity, and high metal ion storage capacity. ${ }^{79}$ Due to their larger atomic size and heavier atomic mass (as compared to lithium) that leads to poor kinetics associated with metal-ion intercalation/deintercalation, the exploration of metal-ion insertion materials is highly limited. ${ }^{5,80,81}$ These metal ions require a large tunnel size for easy diffusion. Organic compounds exhibit better structural flexibility and multiplicity than inorganic compounds. ${ }^{82}$ Hence, organic compounds are considered to be promising candidates as electrode material in MI batteries. According to a report by Wessells et al., ${ }^{83}$ bulk Prussian blue analogues (PBA) nickel hexacyanoferrate nanoparticles have been proven to be promising for the intercalation/ deintercalation of $\mathrm{K}^{+}$and $\mathrm{Na}^{+}$operated in aqueous electrolytes. The electrode shows $67 \%$ retention of its maximum flow rate capacity at a current density of $41.7 \mathrm{C}$ and no noticeable capacity fading over 5000 cycles at the current density of 8.3C is observed when operated in an aqueous sodium electrolyte. Metal cations present in MOFs serve as active sites for promoting redox reactions, and open crystal frames support efficient and reversible extraction/insertion of metal ions. ${ }^{84,85}$ As reported by Yongling An et al., the MOF MIL-125 (Ti) showed promising electrochemical performance with a reversible capacity of $208 \mathrm{~mA} \mathrm{~h} \mathrm{~g}^{-1}$ at $10 \mathrm{~mA} \mathrm{~g}^{-1}$ (Fig. 6a-d). The electrode material also exhibited excellent stability of $90.2 \%$ for over 2000 cycles when employed in a potassium-ion battery with carbonate electrolyte (Fig. 6e). As studied by the ex situ XRD and IR techniques, it was confirmed that the reversible intercalation of the $\mathrm{K}^{+}$ion was 
(a)

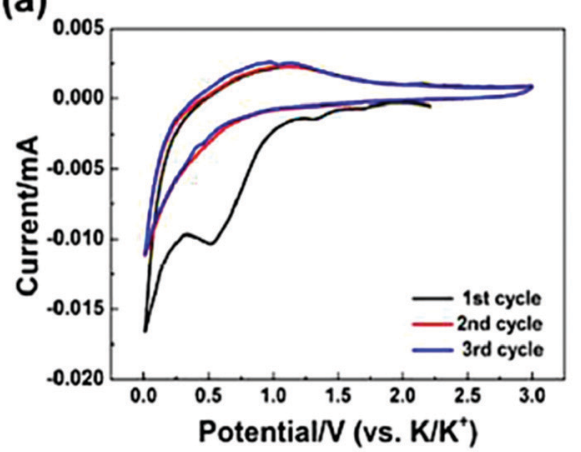

(c)

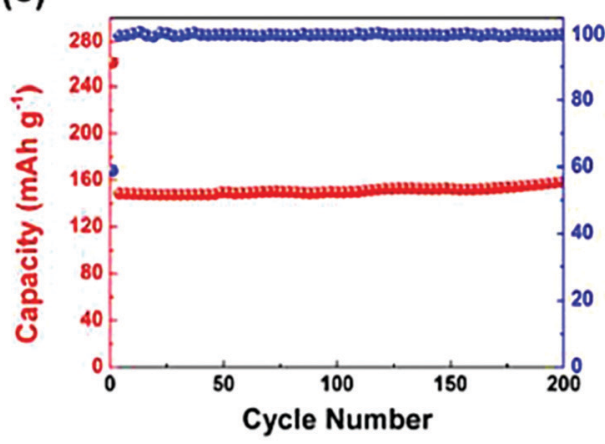

(b)

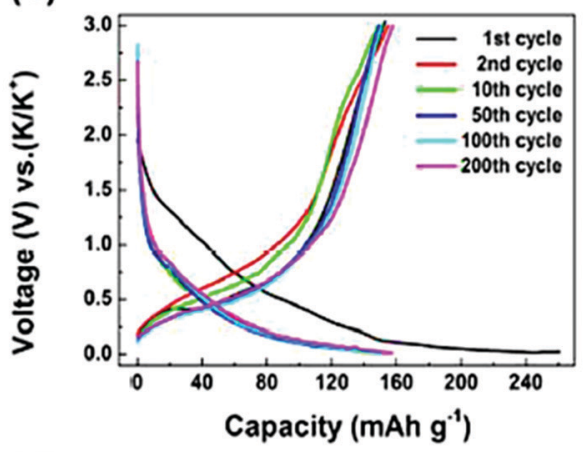

(d)



(e)

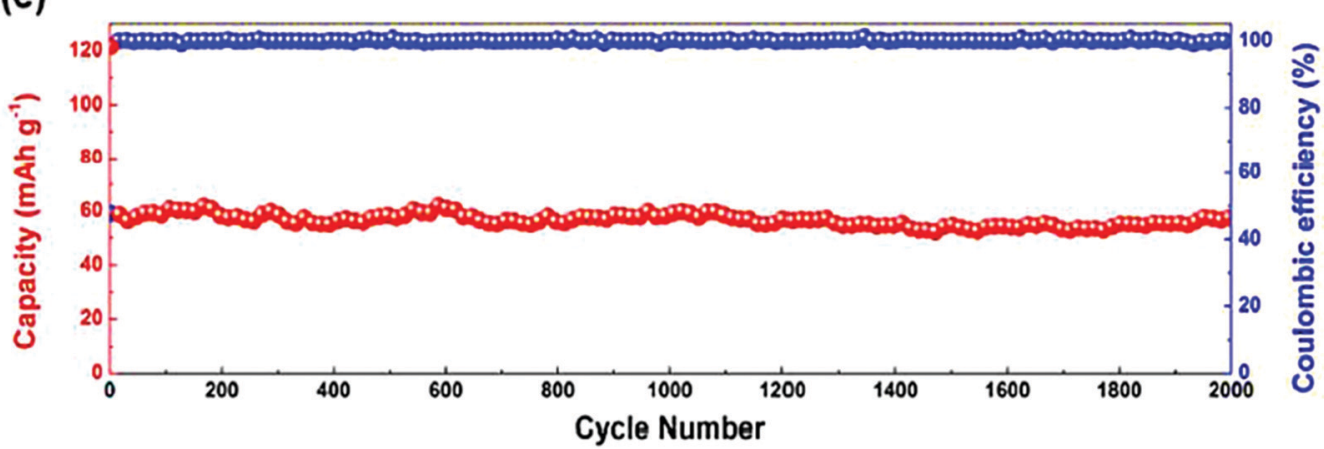

Fig. 6 Electrochemical characteristics of MIL-125 (Ti) MOF as the anode for potassium-ion batteries. (a) Cyclic voltammetry (CV) loops at 0.5 mV s ${ }^{-1}$. (b) Galvanostatic charge-discharge plots at $50 \mathrm{~mA} \mathrm{~g}^{-1}$. (c) Cyclic stability was exhibited at $50 \mathrm{~mA} \mathrm{~g}^{-1}$. (d) Rate performance at various current densities. (e) Long-term cyclic stability at $200 \mathrm{~mA} \mathrm{~g}^{-1}$. Reprinted with permission from ref. 86. Copyright 2017 Royal Society of Chemistry.

associated with the organic moieties without the involvement of Ti sites. ${ }^{86}$

Prussian blue-like materials have garnered significant attention as cathode materials to be implemented in rechargeable aqueous SIBs due to their open-framework structure and remarkable cycling stability in aqueous electrolytes. However, these types of electrodes suffer from low practical specific capacities $\left(\sim 70 \mathrm{~mA} \mathrm{~h} \mathrm{~g}{ }^{-1}\right)$. As reported in a work by Xingde Xiang and co-workers, nanostructured $\mathrm{Na}_{2} \mathrm{Co}_{0.8} \mathrm{Ni}_{0.2}\left(\mathrm{Fe}(\mathrm{CN})_{6}\right)$ compound with concentrated $\mathrm{NaSO}_{3} \mathrm{CF}_{3}$ as an electrolyte was observed to deliver a reversible capacity of $116.4 \mathrm{~mA} \mathrm{~h} \mathrm{~g}^{-1}$ at $50 \mathrm{~mA} \mathrm{~g}^{-1}$, which was associated with a working potential of $0.67 \mathrm{~V}$ ( $v s$. $\mathrm{Ag} / \mathrm{AgCl})$. The co-precipitation for synthesis leads to an open framework structure. This material achieved a high theoretical specific energy, reaching a value of $171 \mathrm{~W} \mathrm{~h} \mathrm{~kg}^{-1}$ when they served as SIBs with the $\mathrm{NaTi}_{2}\left(\mathrm{PO}_{4}\right)_{3}$ anode. In particular, this material showed remarkable cycling performance associated with a capacity retention of $88 \%$ over 100 charging/discharging cycles at $100 \mathrm{~mA} \mathrm{~g}^{-1}$. Furthermore, the reaction mechanism was understood by combining ex situ X-ray diffraction, FTIR spectroscopy, and Raman spectroscopy. It was concluded that there occurs initial structural transformation from the rhombohedral to the cubic phase, which is associated with a subsequent solid-solution mechanism in a broad potential range via the reversible chemistry of $\mathrm{Fe}^{3+} / \mathrm{Fe}^{2+}$ and $\mathrm{Co}^{3+} / \mathrm{Co}^{2+}$ redox couples. $^{87}$

Further, Zhenan Bao and co-workers reported a cobalt-based 2D conductive MOF, Co-HAB, exhibiting dense, stable, and accessible active sites, resulting in the associated high-power energy storage device as a result of the conjugative coordination in between the $\mathrm{Co}(\mathrm{II})$ center and the redox-active linker 
hexaaminobenzene (HAB). Due to the remarkable ability of $\mathrm{Co}-\mathrm{HAB}$ to stabilize reactive $\mathrm{HAB}$, the three-electron redox reaction for one single $\mathrm{HAB}$ was demonstrated. For Co-HAB, with the help of synthetic tunability, the bulk electrical conductivity of $1.57 \mathrm{~S} \mathrm{~cm}^{-1}$ was reached, resulting in an extremely large rate capability, delivering $214 \mathrm{~mA} \mathrm{~h} \mathrm{~g}^{-1}$ within $7 \mathrm{~min}$. Meanwhile, almost linear enhancement of the areal capacity was observed on increasing the active mass loading up to $9.6 \mathrm{mg} \mathrm{cm}^{-2}$, showing $2.6 \mathrm{~mA} \mathrm{~h} \mathrm{~cm}{ }^{-2}$ for a small amount of conducting agent. ${ }^{88}$ Bingwen $\mathrm{Hu}$ and co-workers reported the development of cobalt(II) terephthalate-based MOF (coded as ' $\mathrm{L}-\mathrm{Co}_{2}(\mathrm{OH})_{2} \mathrm{BDC}$ '), (BDC = 1,4-benzenedicarboxylate) using the hydrothermal method, which was implemented as an anode material for K-ion batteries (Fig. 6). Hydrothermal synthesis leads to the crystallization of the MOF, which gives a homogenous continuous structure for ion transportation and hence improves the charge storage capacity. The potassium storage performance of $\mathrm{L}^{-} \mathrm{Co}_{2}(\mathrm{OH})_{2} \mathrm{BDC}$ was outstanding, reaching a large reversible capacity of $188 \mathrm{~mA} \mathrm{~h} \mathrm{~g}^{-1}$ over 600 cycles at $1 \mathrm{~A} \mathrm{~g}^{-1}$, thus unraveling the substantial potential of MOFs as potassium storage anodes. Furthermore, the investigation of the redox chemistry of $\mathrm{L}_{-} \mathrm{Co}_{2}(\mathrm{OH})_{2} \mathrm{BDC}$ with the help of soft X-ray spectroscopy and X-ray absorption near-edge structure techniques validated that both the organic linkers and Co centers took part in potassium storage. The coordination between cobalt and oxygen ions crucially ensured the reversibility of potassium de-intercalation and intercalation reactions. ${ }^{89}$

6.1.2 MOF-derived materials for MI batteries. Several reports are available where MOF-derived materials (oxides, sulfides, selenides, MOF-derived composites) have been actively used as electrode materials for Na- and K-ion batteries, apart from $\mathrm{Li}$-ion batteries. Not the pristine form but also MOF-derived materials such as MOF derived metal oxides, MOF derived carbon, and a composite of MOFs have been exclusively studied for exploring their performance in MI batteries. The following sections include a brief overview of the various MOF-based materials that have been used in various MI batteries:

6.1.2.1 MOF-derived oxides for MI batteries. MI batteries often exhibit much slower reaction kinetics and more significant volume change while the charge/discharge process is attributed to larger atomic size of the metal ions. Porosity modification, pore feature modifications, structural and surface composition manipulation for electrode materials consist of some typical strategies to enhance the conversion reaction kinetics, augment the electronic conductivity, and adapt to the volumetric fluctuation. MOFs have proved to be a very attractive precursor and several reports are available where MOF-derived metal oxides have been used as anodes in the MI batteries. Oxides are considered to be promising electrode materials for MI batteries due to their intrinsic safety and large theoretical capacity. ${ }^{90}$ Metal oxides derived from MOFs have several advantages such as easy synthesis, structural tunability, large porosity, high specific capacity, and good stability. ${ }^{91}$

Wu et al. ${ }^{92}$ reported the study of vacancy-free $\mathrm{Na}_{x} \mathrm{CoFe}(\mathrm{CN})_{6}$ (NaCoHCF) nanocrystals by means of controlling the crystallization and as a sodium storage material in aqueous electrolyte. Benefiting from its great lattice and crystal integrity, the obtained electrode material was found to have a high capacity of $130 \mathrm{~mA} \mathrm{~h} \mathrm{~g}^{-1}$ with a capacity retention of $90 \%$ after 800 cycles. These results show that PBA can be an efficient highperformance commercially-viable electrode material owing to its scalable production and operation in low-cost aqueous electrolyte for large-scale energy storage applications. ${ }^{93}$ Multiphase compounds are perceived to exhibit good electrochemical performance for energy storage applications. As reported by Guozhao Fang and co-workers, a bimetallic selenide heterostructure $\left(\mathrm{CoSe}_{2} / \mathrm{ZnSe}\right)$ has been studied as the anode material in the Na-ion battery with $1 \mathrm{M} \mathrm{KOH}$ electrolyte with excellent electrochemical performance (Fig. 7a-e). An outstanding sodium storage ability was showcased by this material along with an excellent cyclic stability of 800 cycles, corresponding to the full cell of $\mathrm{Na}_{3} \mathrm{~V}_{2}\left(\mathrm{PO}_{4}\right)_{3} \| \mathrm{CoZn}-\mathrm{Se}$ (Fig. 7f and g). The work significantly demonstrated the role of phase boundaries associated with the metallic compounds, which resulted in boosted electrochemical performance. $^{94}$

However, battery operation in aqueous electrolytes restricts the battery voltage stability to $1.5 \mathrm{~V}$ as it is the electrochemical stability window for $\mathrm{H}_{2} \mathrm{O}$. Various potassium batteries, their analogs $\left(\mathrm{KMFe}(\mathrm{CN})_{6}, \mathrm{M}=\mathrm{Fe}, \mathrm{Mn}, \mathrm{Ni}, \mathrm{Cu}, \mathrm{Co}\right.$, and $\left.\mathrm{Zn}\right)$, and the inexpensive $\mathrm{Na}_{x} \mathrm{MnFe}(\mathrm{CN})_{6}$ have been studied as cathode materials for Na-ion batteries with non-aqueous electrolytes (saturated $\mathrm{NaClO}_{4}$ in 1:1 EC/DEC (vol: vol)). ${ }^{95,96}$ According to a recent report by Wang et al., ${ }^{95}$ hydrothermally synthesized iron-oxalate 3D framework $\left(\mathrm{K}_{4} \mathrm{Na}_{2}\left(\mathrm{Fe}\left(\mathrm{C}_{2} \mathrm{O}_{4}\right)_{2}\right)_{3} \cdot 2 \mathrm{H}_{2} \mathrm{O}\right)$ showed excellent reversible $\mathrm{Na}^{+}$ intercalation/deintercalation reactions. The $\left(\mathrm{K}_{4} \mathrm{Na}_{2}\left(\mathrm{Fe}\left(\mathrm{C}_{2} \mathrm{O}_{4}\right)_{2}\right)_{3}\right.$. $2 \mathrm{H}_{2} \mathrm{O}$ ) framework possessed $1 \mathrm{D}$ to unsealed channels in the oxalato-bridged structure, which could cause ion approachability of two $\mathrm{Na}^{+}$in each formula unit. This discovery as a novel material for ion intercalation is highly attractive due to its significant prospects, regarding applications in MI batteries. ${ }^{97}$ In another report by G. Zou et al., the in situ pyrolysis method on titanium-based MOF $\left(\mathrm{Ti}_{8} \mathrm{O}_{8}(\mathrm{OH})_{4}\right)^{98}$ resulted in carbon-coated rutile titanium dioxide anode material for Na-ion storage, exhibiting a reversible capacity of $\sim 175 \mathrm{~mA} \mathrm{~h} \mathrm{~g}{ }^{-1}$. The cyclic stability was also outstanding with a retention of $\sim 70 \mathrm{~mA} \mathrm{~h} \mathrm{~g}^{-1}$ of the specific capacity after 2000 cycles. This improved performance could be attributed to the $\mathrm{Ti}-\mathrm{O}-\mathrm{C}$ skeleton structure coming from the Ti-based MOF. ${ }^{98}$ In another report by Zhen Zhang et al., hollow cupric oxide (CuO) spheres were prepared by annealing an HKUST-1 MOF that has been studied as an anode material for Na-ion battery, exhibiting $612 \mathrm{~mA} \mathrm{~h} \mathrm{~g}^{-1}$ of reversible capacity with a retention of $83 \%$ over 50 cycles. ${ }^{99}$ Multiple-metal compounds have shown tremendous promising aspects as anode materials for MI batteries. As reported by Yuan Guo et al., ${ }^{9}$ hollow $\mathrm{MgFe}_{2} \mathrm{O}_{4}$ micro-boxes synthesized using MOFs Prussian blue microcubes as self-sacrificial templates have shown excellent Na-ion diffusion path and enough space for volume expansion accommodation as the intercalation/deintercalation of Na-ion proceeds. The obtained bimetallic oxide $\left(\mathrm{MgFe}_{2} \mathrm{O}_{4}\right)$ micro-boxes showed a capacity of $406 \mathrm{~mA} \mathrm{~h} \mathrm{~g}{ }^{-1}$ and could maintain a reversible capacity of $135 \mathrm{~mA} \mathrm{~h} \mathrm{~g}^{-1}$ over 150 cycles, as shown in Fig. 8a-d. ${ }^{9}$ 

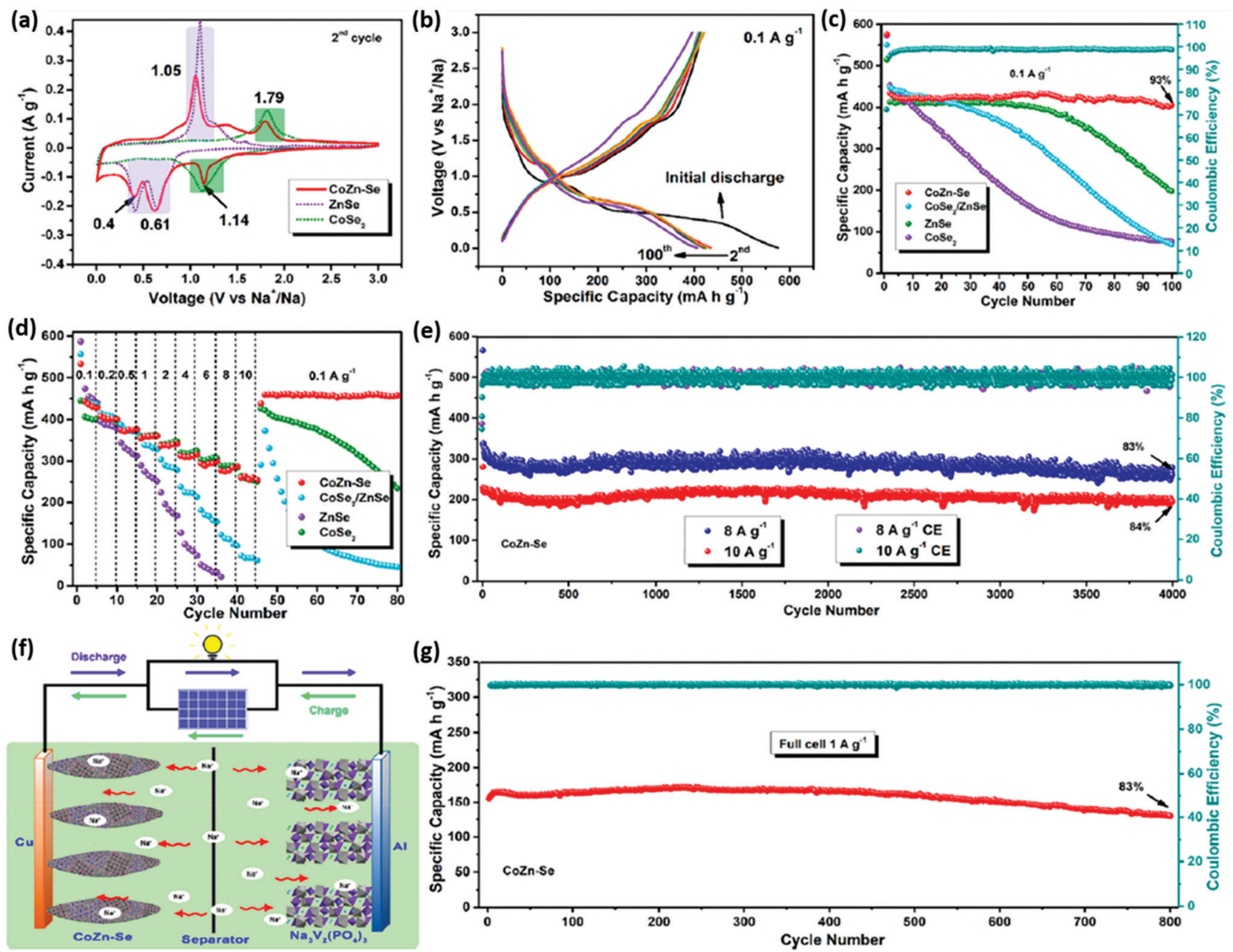

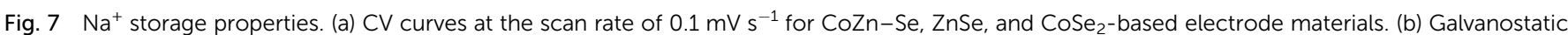
charge-discharge potential profiles at $0.1 \mathrm{~A} \mathrm{~g}^{-1}$ of CoZn-Se. (c) Cycling performance at $0.1 \mathrm{~A} \mathrm{~g}^{-1}$. (d) Rate capability at various current densities of the electrode materials. (e) Cycling stability performance of CoZn-Se. (f) Schematic representation of the $\mathrm{Na}_{3} \mathrm{~V}_{2}\left(\mathrm{PO}_{4}\right)_{3} \| \mathrm{CoZn}-\mathrm{Se}$ full cell. (g) Cyclic stability at $1 \mathrm{~A} \mathrm{~g}^{-1}$ of the full cell. Reprinted with permission from ref. 94. Copyright 2019 American Chemical Society.

According to a report by Chao Li et al., a layered MOF based on cobalt(II) terephthalate $\left(\mathrm{L}-\mathrm{Co}_{2}(\mathrm{OH})_{2} \mathrm{BDC}, \mathrm{BDC}=1,4\right.$-benzenedicarboxylate) has been tested as an anode material for K-ion batteries (Fig. 9a-d) with a large reversible capacity of $188 \mathrm{~mA} \mathrm{~h} \mathrm{~g}^{-1}$ over 600 cycles at a current density of $1 \mathrm{Ag}^{-1}$, as shown in Fig. 9e. ${ }^{89}$

6.1.2.2 MOF-derived carbon/doped carbon materials for MI batteries. Mesoporous carbon can significantly enhance the reaction kinetics and performance for metal ion storage. Nevertheless, the conventional synthetic method for such nanostructured carbon is obtained through template-based synthesis using silica and is not scalable. The direct pyrolysis of MOFs shows promising aspects in paving a path for the easy and facile synthesis of porous carbon controllable porosity and the pore features along with a large surface area. ${ }^{100}$ As reported by Xiaoli Ge et al., ZIF-67 MOF-derived phosphatized CoP@C polyhedrons integrated with reduced graphene oxide (RGO) having nickel foam (NF) as the substrate (CoP@C-RGO-NF anode) exhibited an extraordinary electrochemical performance with a specific capacity of $473.1 \mathrm{~mA} \mathrm{~h} \mathrm{~g}^{-1}$ with a cycling stability over 100 cycles when tested for Na-ion storage. ${ }^{27}$ In another report by Nolan Ingersoll et al., MOF5 $\left(\mathrm{Zn}_{4} \mathrm{O}(1,4 \text {-benzodicarboxylate) })_{3}\right)$ (MOF5DC) and ZIF8 (Zn(2-methylimidazole) $)_{2}$ ) (ZIF8DC)-derived highly porous and robust carbons showed half-cell discharge capacity values of 227 and $107 \mathrm{~mA} \mathrm{~h} \mathrm{~g}^{-1}$, respectively. The capacity retention of $84-89 \%$ over 66 cycles for the MOFDC anodes affirms the structural robustness. As understood from the discharge profiles for both MOF5DC and ZIF8DC, the primary storage proceeded through adsorption at the defect sites. ${ }^{101}$ In another report by Xiaodong Shi et al., sulfur-doped mesoporous carbon (SPC) derived from MOF-5 exhibited a reversible discharge capacity of $174 \mathrm{~mA} \mathrm{~h} \mathrm{~g}{ }^{-1}$ over 500 cycles. The augmented electrochemical performances are mainly credited to the incorporation of $\mathrm{S}$ atoms into the carbon frame, which effectively increases the interlayer distance, in turn improving the electronic conductivity and promoting the intercalation/deintercalation 

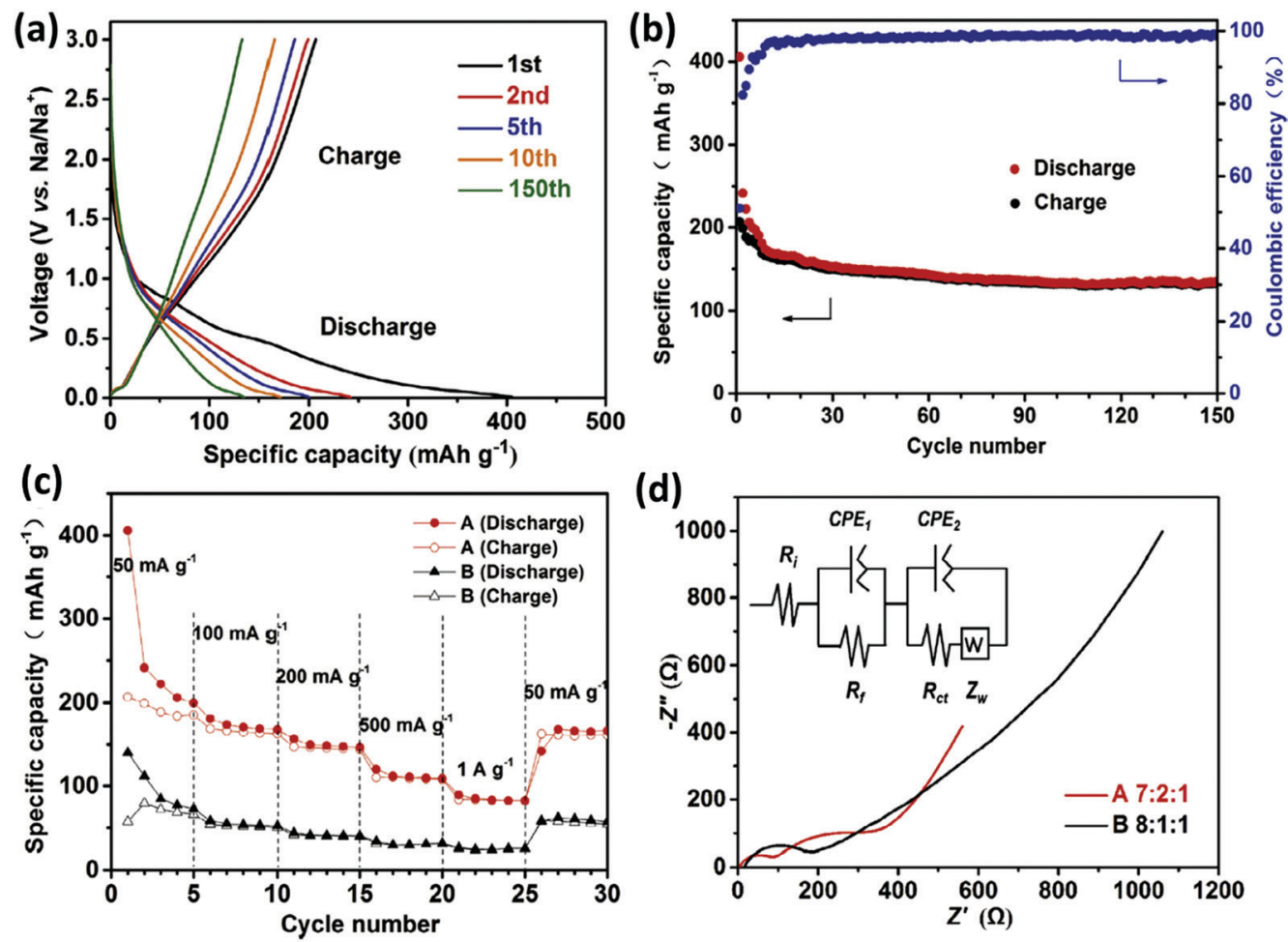

Fig. 8 Electrochemical performance corresponding to $\mathrm{MgFe}_{2} \mathrm{O}_{4}$ micro-box electrodes with varying ratios of the active material, viz., $\mathrm{A}(7: 2: 1)$ and $\mathrm{B}$ (8:1:1). (a) Discharge-charge potential profiles and (b) cyclic stability performance at $50 \mathrm{~mA} \mathrm{~g}^{-1}$ of sample $\mathrm{A}$; (c) rate capability and (d) Nyquist plots corresponding to samples A and B. Reprinted with permission from ref. 9. Copyright 2017 Elsevier.

(a)

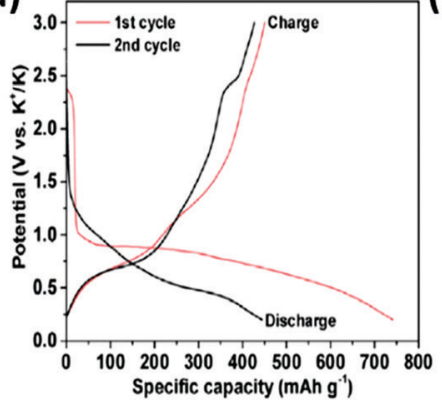

(d)



(b)

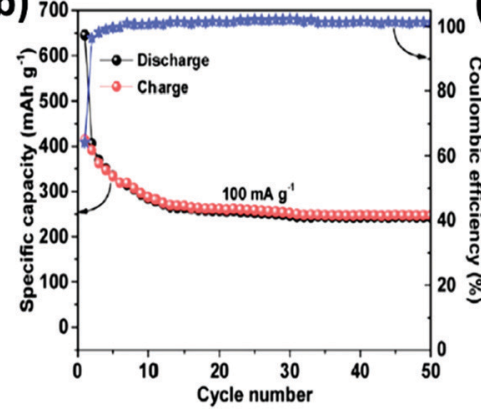

(e) 700



Fig. 9 Electrochemical performance of the $\mathrm{L}-\mathrm{CO}_{2}(\mathrm{OH})_{2} \mathrm{BDC}$ electrode for $\mathrm{K}$-ion storage (in half-cell configuration): (a) galvanostatic discharge-charge potential profiles; (b and c) cycling stability at current densities of $100 \mathrm{~mA} \mathrm{~g}^{-1}$ and $200 \mathrm{~mA} \mathrm{~g}^{-1}$, respectively; (d) Coulombic efficiency and rate capability at different current densities varying from 50 to $1000 \mathrm{~mA} \mathrm{~g}^{-1}$; (e) Coulombic efficiency and long term cyclic stability at $1 \mathrm{~A} \mathrm{~g}^{-1}$, where the activation of the electrode was achieved by the application of $100 \mathrm{~mA} \mathrm{~g}^{-1}$ in the first 3 cycles. Reprinted with permission from ref. 89 . Copyright 2017 Elsevier. 
process of sodium storage. ${ }^{102}$ Reports are also available wherein MOF-derived carbon have been used as anode materials for K-ion batteries. In a report by Peixun Xiong et al., nitrogendoped carbon nanotubes (NCNTs) obtained by pyrolyzing cobaltcontaining MOFs as anodes of K-ion batteries exhibited high capacity retention of $102 \mathrm{~mA} \mathrm{~h} \mathrm{~g}{ }^{-1}$ along with a high rate capability. The stability was also remarkable with no noticeable capacity loss over 500 cycles. ${ }^{103}$ In a recent report by Xuefeng Zhou et al., 3D ordered macroporous ZIF-8 was carbonized to synthesize 3D interconnected $\mathrm{N}$-doped hierarchical porous carbon (N-HPC) as the anode material, which showed excellent rate performance ( $94 \mathrm{~mA} \mathrm{~h} \mathrm{~g}^{-1}$ at $10.0 \mathrm{~A} \mathrm{~g}^{-1}$ ) and an unprecedentedly long cycle life corresponding to $157 \mathrm{~mA} \mathrm{~g}^{-1}$ after 12000 cycles at $2.0 \mathrm{~A} \mathrm{~g}^{-1}$, together with a greater reversible capacity of $292 \mathrm{~mA} \mathrm{~h} \mathrm{~g}^{-1}$ at $0.1 \mathrm{~A} \mathrm{~g}^{-1}$. The 3D interpenetrating morphology proved to be beneficial overall, demonstrating superiority in energy storage applications. ${ }^{104}$

6.1.2.3 MOF-based composites for MI batteries. MOFs have been widely applied in new-generation MI batteries but the electrochemical reaction process, the mechanism driving energy storage, and the implications of the structure on the metal-ion storage performance still need to be understood. In the case of MOF-derived carbon, the implications of the pore features, specific surface area, heteroatom doping, and pore volume on the metal ion storage capacity need to be studied thoroughly. A fundamental understanding can then serve as the basis for designing high-performance electrode materials for MI batteries. As reported by Xinye Liu et al., binary Ni/Co MOFs (Ni-Co-MOF)derived $\mathrm{Ni}_{3} \mathrm{~S}_{2} / \mathrm{Co}_{9} \mathrm{~S}_{8} / \mathrm{N}$-doped carbon composite showed an excellent reversible specific capacity of $420 \mathrm{~mA} \mathrm{~h} \mathrm{~g}^{-1}$ along with an outstanding capacity retention of $98.6 \%$ for Na-ion storage (Fig. 10a-f). As a result of the nano-scaled morphology, the obtained material possesses the requisite profile for an excellent anode material: ultrafine molecules $\left(\mathrm{Ni}_{3} \mathrm{~S}_{2}\right.$ and $\mathrm{Co}_{9} \mathrm{~S}_{8}$ particles) ( $\sim 7 \mathrm{~nm})$, a hollow and highly porous morphology, and a very thin $\mathrm{N}$-doped carbon coating. ${ }^{105}$

In another report by Xijun Xu et al., a facile MOF-derived selenidation method was implemented to synthesize carbonencaptured selenides as superior anodes for Na-ion battery. Peapod-like $\mathrm{Fe}_{7} \mathrm{Se}_{8} @ \mathrm{C}$ nanorods exhibited a high specific capacity of $218 \mathrm{~mA} \mathrm{~h} \mathrm{~g}^{-1}$ over 500 cycles while the porous NiSe@C spheres displayed a large specific capacity of $160 \mathrm{~mA} \mathrm{~h} \mathrm{~g}^{-1}$ over 2000 cycles. This work showed the possibility of this facile

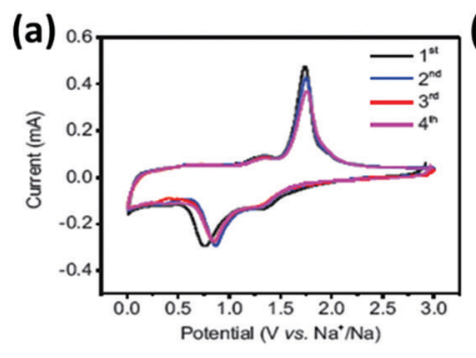

(d)

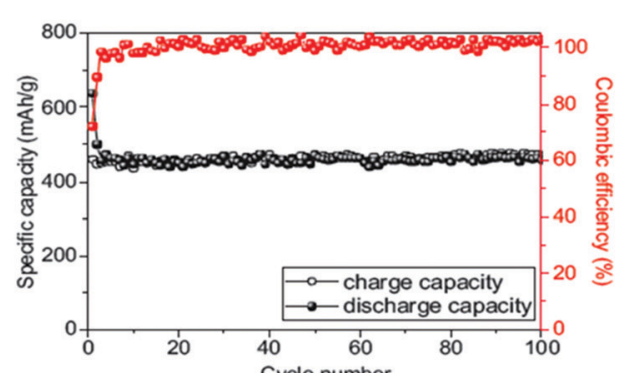

(c)



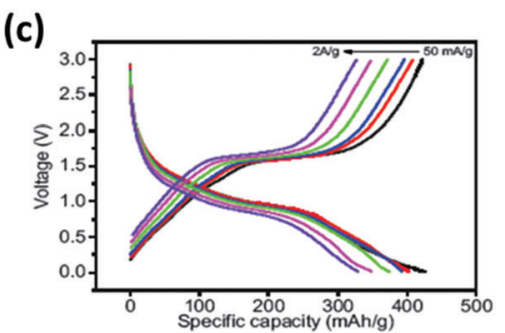

(e)

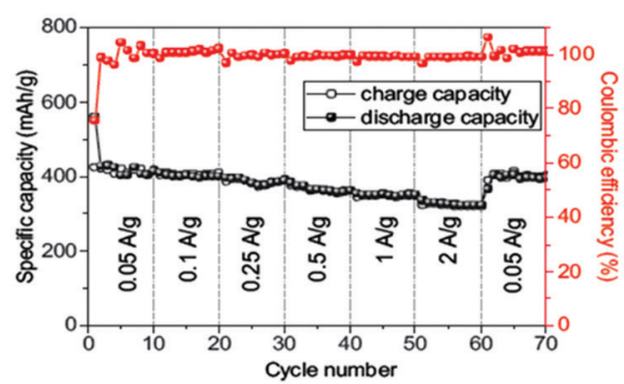

(f)

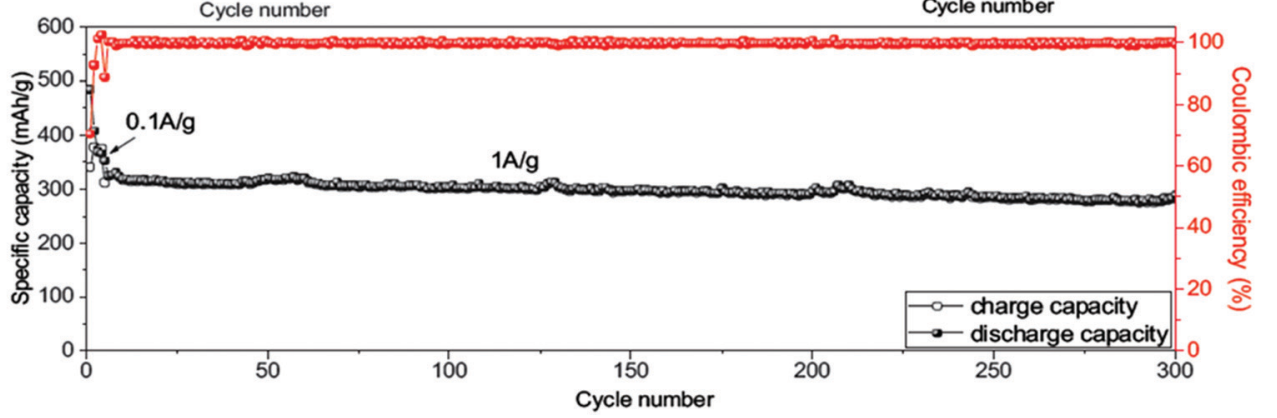

Fig. 10 Electrochemical charge storage properties of the $\mathrm{Ni}_{3} \mathrm{~S}_{2} / \mathrm{Co} 09 \mathrm{~S} 8 / \mathrm{N}$-doped carbon composite. (a) Cyclic voltammetry plots for the measurement carried out at $0.2 \mathrm{mV} \mathrm{s}^{-1}$. (b) Charge/discharge profile at $0.1 \mathrm{~A} \mathrm{~g}^{-1}$. (c) Charge/discharge potential profiles at various C-rates. (d) The long-term cyclic stability performance at $0.1 \mathrm{~A} \mathrm{~g}^{-1}$ with a capacity retention of $98.6 \%$ after 100 cycles. (e) C-rate performance exhibited at current densities varying between $0.05 \mathrm{~A} \mathrm{~g}^{-1}$ and $2 \mathrm{~A} \mathrm{~g}^{-1}$, exhibiting an average capacity of $323 \mathrm{~mA} \mathrm{~h} \mathrm{~g}^{-1}$ at a current rate of $2 \mathrm{~A} \mathrm{~g}^{-1}$. (f) Long-term cyclic stability at the high current rate of $1 \mathrm{~A} \mathrm{~g}^{-1}$. Reprinted with permission from ref. 105. Copyright 2017 Royal Society of Chemistry. 
MOF-derived material strategy to serve as a promising method for boosting the synthesis of new functional inorganic materials meant for catalysis, sensors, and energy storage. ${ }^{106}$ In another report by Yuan Wang et al., $\mathrm{ZnO} /$ reduced $\mathrm{RGO} /$ carbon $(\mathrm{ZnO} / \mathrm{rGO} / \mathrm{C})$ composite was reported to exhibit a large reversible capacity of $300 \mathrm{~mA} \mathrm{~h} \mathrm{~g}{ }^{-1}$ after 100 cycles when tested as an anode material for Na-ion battery. ${ }^{107}$ In another report by Shihua Dong et al., ZIF-8 derived $\mathrm{ZnS}-\mathrm{Sb}_{2} \mathrm{~S}_{3} @ \mathrm{C}$ core-double shell polyhedrons, when tested as the anode for Na-ion battery, showed remarkably improved specific capacity along with stable cycle stability and high Coulombic efficiency. ${ }^{108}$ As also reported by Yew Von Lim et al., transition metal phosphides, such as iron phosphide (FeP), have shown great potential of performing as promising high-performance electrode materials for $\mathrm{Na}$-ion batteries due to their outstanding energy storage abilities. Porous FeP/C nanostructures exhibited extraordinary Na storage properties by exhibiting high capacity ( $410 \mathrm{~mA} \mathrm{~h} \mathrm{~g}{ }^{-1}$ ), outstanding rate capacity, and large cycle life (over 200 cycles). These results revealed the promising prospect of MOF-derived $\mathrm{FeP} / \mathrm{C}$ composite as an anode material for Na-ion batteries. ${ }^{109}$ In another report by Wei Shuang et al., uniformly distributed $\mathrm{Ni}_{3} \mathrm{~S}_{2}$ nanoparticles within $\mathrm{N}$-doped carbon nanosheets $\left(\mathrm{Ni}_{3} \mathrm{~S}_{2} @ \mathrm{C}\right)$ obtained by the means of sulfuration of a Ni-MOF and polypyrrole (PPy) coating exhibited a large discharge capacity of $432.8 \mathrm{~mA} \mathrm{~h} \mathrm{~g}{ }^{-1}$ over 100 charge-discharge cycles along with a remarkable rate capacity of $371.6 \mathrm{~mA} \mathrm{~h} \mathrm{~g}^{-1}$ at $6.4 \mathrm{~A} \mathrm{~g}^{-1}$. To the best of our knowledge and as also claimed by the authors, the obtained NiS $@$ @-600 nanosheets exhibited the best rate performance amongst all the $\mathrm{Ni}_{3} \mathrm{~S}_{2}$ composites reported to date. ${ }^{110}$

\subsection{Use of MOFs in MS batteries}

It is worth mentioning that though the application of pristine MOF as a sulfur host for MS battery system has shown interesting results, the results still lack the required level of performance for practical applicability. This is attributed to the poor stability of MOF and low conductivity. Nevertheless, MOFs have also emerged as precursors/templates for the synthesis of porous carbon and carbon derivatives. Cheetham's group pioneered the MOF-derived carbon synthesis with diverse hierarchical pores derived from four different zinc-based MOFs (ZIF-8, RT-MOF-5, solve-MOF-5, and Zn-Fumarate) for sulfur encapsulation and the report was published in $2013 .^{28}$ It has been reported that the MOF-derived carbon materials, when acting as the sulfur host for the MS battery, can largely enhance the conductivity, together with the effective restriction of the dissolution of polysulfides, leading to an enhancement in the specific capacity value and retention. ${ }^{111}$ The following section projects some remarkable work involving MOF-based sulfur hosts for various non-lithium MS batteries. Further, the doping effect in carbon-derived MOFs for the successful encapsulation of sulfur for designing the $\mathrm{Na}-\mathrm{S}$ battery has also been revealed by Y. M. Chen et al., through the fabrication of nanoporous nitrogen-doped carbon matrix by the carbonization of ZIF-8 precursors. The ZIF-8/S composite cathode exhibited good electrochemical performance and the designed battery showed a reversible specific capacity of $\sim 1000 \mathrm{~mA} \mathrm{~h} \mathrm{~g}^{-1}$ (Fig. 11a and b).
The battery could retain a specific capacity of $500 \mathrm{~mA} \mathrm{~h} \mathrm{~g}^{-1}$ after 250 cycles at a rate of $0.2 \mathrm{C}$ (Fig. 11c). ${ }^{112}$

In another report by S. Wei et al., the importance of porosity in the host for sulfur encapsulation for the design of the $\mathrm{Na}-\mathrm{S}$ battery was demonstrated through the utilization of a ZIF-8 MOF-derived microporous carbon-sulfur composite cathode. The report demonstrates that the designed cells exhibited a reversible capacity of $600 \mathrm{~mA} \mathrm{~h}^{-1}$ with an excellent Coulombic efficiency of $\sim 100 .{ }^{113}$ Reports are also available where MOFderived carbon has also been used as the sulfur host in the Al-sulfur battery, which is another promising next-generation MS battery mode due to its large theoretical capacity of $1672 \mathrm{~mA} \mathrm{~h} \mathrm{~g}{ }^{-1}$. However, the commercialization of these batteries is still far from realization due to their low stability and lifespan. Reports are available wherein MOF-derived carbon could be used for sulfur encapsulation to effectively enhance the stability of the Al-S battery. As reported by Y. Guo et al., a composite cathode based on sulfur anchored on a carbonized HKUST1 matrix could maintain a reversible capacity of $600 \mathrm{~mA} \mathrm{~h} \mathrm{~g}$ after the 75th cycle. Further, this could maintain a reversible capacity of $460 \mathrm{~mA} \mathrm{~h} \mathrm{~g}^{-1}$ after the 500th cycle at a current density of $1 \mathrm{~A} \mathrm{~g}^{-1}$, which is associated with a Coulombic efficiency of about $95 \% .{ }^{114}$ Apart from sulfur encapsulation, amending the cell's configuration also shows promising attributes to improve the battery performance, stability, and safety. It has been reported by Manthiram's group that the introduction of a carbon interlayer between the separator and the cathode implemented Li-S battery exhibited enhanced electrochemical performance. Further, in another report, they also demonstrated the electrochemical studies of the Li-S battery associated with a sulfur cathode filled within a carbon nanofiber matrix and a CNF-coated separator. The utility of the modified CNF separator was minimizing the passage of polysulfide to the anode by perpetually entrapping the polysulfide intermediates. The separator also enhanced sulfur utilization by acting as upper current collectors. The discharge capacity reported for the system was $1200 \mathrm{~mA} \mathrm{~h} \mathrm{~g}^{-1}$, exhibiting an outstanding stability for the first 20 cycles, which was unique for this modified cell. The authors credited the reactivation of the so-called "dead" sulfur during the charging and discharging cycles by the coating layer of the separator, which diffused out of conductive substrates. ${ }^{115}$ A few more reports are available where modifying the separator demonstrated an enhancement in the stability of the Li-S battery. In a report by J. Wang et al., an imine-based MOF with a pore size of $0.56 \mathrm{~nm}$ was applied to coat the ceramic separator and the corresponding cell showed an initial discharge capacity of $1415 \mathrm{~mA} \mathrm{~h} \mathrm{~g}^{-1}$ (Fig. 12a-d). The capacity retention was $1000 \mathrm{~mA} \mathrm{~h} \mathrm{~g}^{-1}$ after 100 cycles at $0.5 \mathrm{C}$ and 2C, as shown in Fig. 12d-f. ${ }^{116}$

Z. Chang et al. have explored the measures related to the retardation of the initial "sulfur loss" and exacerbated the voltage polarization to improve the cell performance, besides considering minimizing the polysulfide effect in MS batteries. ${ }^{117}$ Certain advances in MS batteries need a blend of better cathode configurations and other modified battery designs. Besides all these, the discovery of efficient electrolytes that can transport metal ions together with providing compatibility with other cell components 



Fig. 11 (a) C-rate performance exhibited at various current densities by the $\mathrm{N}$-doped carbonized ZIF-8 MOF. (b) Discharge potential profiles at varying $\mathrm{C}$-rates of the $\mathrm{Na}-\mathrm{S}$ cell with ZIF-8-derived $\mathrm{N}$-doped carbon electrode. (c) Long-term cyclic stability as exhibited by the $\mathrm{Na}-\mathrm{S}$ cell at $0.1 \mathrm{C}$ for the first 5 cycles, followed by $0.2 \mathrm{C}$ up to 250 cycles, exhibiting $60 \%$ capacity retention after 250 cycles. Reproduced with permission from ref. 112 . Copyright 2016 Royal Society of Chemistry.

is also mandatory. Remarkable achievements are predictable if further innovations in the electrolyte are realized. ${ }^{118}$

\subsection{Use of MOFs and MOF-derived materials in MA batteries}

We have discussed earlier the various concerns that limit the performance of MA batteries. The reaction kinetics ORR, as well as OER associated with the cathode, are significantly responsible for determining the performance of MA batteries. MOFs find their use as a bifunctional electrocatalyst and as an aircathode material to enhance the stability performance of the MA batteries by altering the reaction kinetics at the cathode. This section outlines the reports that have been published, which project the use of MOFs as electrocatalysts and cathode materials. As already discussed, the efficiency of an MA battery profoundly depends on two fundamental electrocatalytic reactions, i.e., ORR and OER. Both these reactions take place at the air-cathode while the battery discharging and charging processes occur. Due to their unique properties such as crystalline porous structures, tunable metal centers, organic linkers, and coordination structure, MOFs and MOF-derived materials show enormous possibilities to act as catalysts and speed up the sluggish redox reactions at the cathodes of MA batteries. MOFs are of particular interest as they can serve as bifunctional catalysts, improving both the OER as well as the ORR reactions occurring at the air-cathode. The aforementioned properties of the MOFs can influence the bifunctional catalytic performance of any material through either non-specific or specific approaches. The "non-specific approaches" include enhancing the materials' catalytic performance in both ORR and OER. On the other hand, "specific approaches" influence the materials' bifunctional properties by creating different active sites, following different catalytic mechanisms for ORR and OER. This section aims to provide a conclusive overview of the merits and uniqueness of MOFs and MOF-derived materials (including specific examples and their performance data) acting as bifunctional catalysts for MA batteries. ${ }^{119}$ Several reports are available wherein MOFs and MOF-derived materials are used as bifunctional catalysts for $\mathrm{Zn}$-air batteries. As reported by S. S. Sindhe et al., hexaiminobenzene MOF (Mn/Fe-HIB-MOF) could act as an outstanding bifunctional oxygen electrocatalyst and has been implemented in an aqueous and flexible $\mathrm{Zn}$-air battery with functionalized bio-cellulose electrolytes (Fig. 13a). ${ }^{120} \mathrm{Mn} / \mathrm{Fe}-$ HIB-MOF exhibited superior bifunctional oxygen electrocatalytic activity $(0.627 \mathrm{~V})$ with half-wave potential $(0.883 \mathrm{~V})$ for oxygen reduction and overpotential (280 $\mathrm{mV} @ 10 \mathrm{~mA} \mathrm{~cm}^{-2}$ ) for oxygen evolution reactions, outperforming commercial Pt/C and $\mathrm{RuO}_{2}$. Notably, as claimed by the authors, the Zn-air battery associated with such an air-cathode exhibited the highest lifetime $(1000 \mathrm{~h}$ over 6000 cycles) reported to date for liquid rechargeable $\mathrm{Zn}$-air batteries (Fig. 13b and d). For the first time, the efficiency of a $\mathrm{Zn}-$ air battery could reach $65.24 \%$ at $25 \mathrm{~mA} \mathrm{~cm} \mathrm{~cm}^{-2}$ (Fig. 13c). For allsolid-state flexible configuration also, the lifetime outperformed 

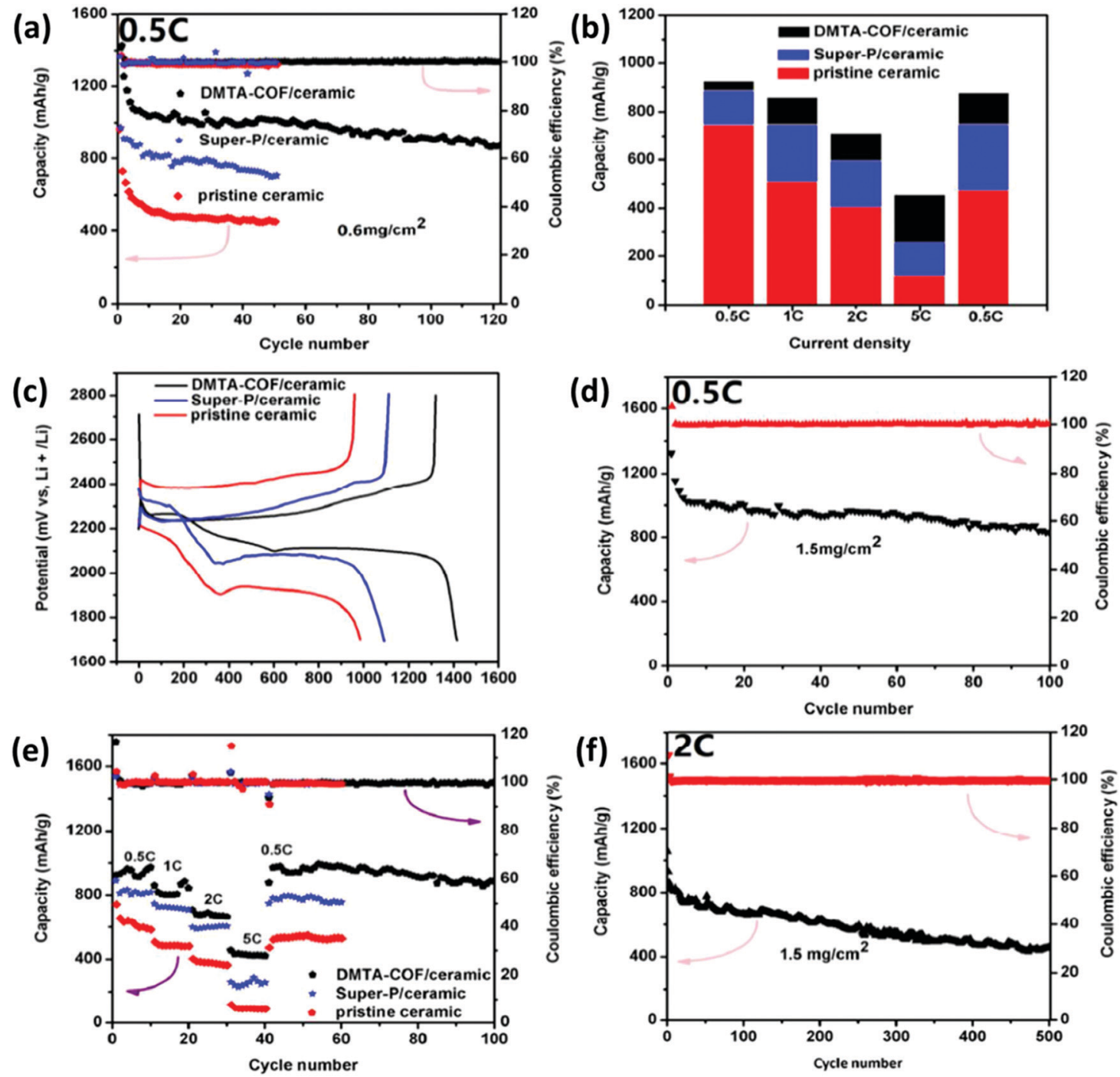

Fig. 12 Electrochemical performance of Li-S batteries with various ceramic separators. (a) Cycling performance of the Li-S battery with various MOFbased ceramic separators at $0.5 \mathrm{C}$. (b) Galvanostatic charge-discharge potential at $0.5 \mathrm{C}$. (c) The discharge capacity as obtained at different $\mathrm{C}$-rates. (d) Column diagram for the capacity contribution at various rates. (e) Cycling characteristics of the cathode with $1.5 \mathrm{mg} \mathrm{cm}^{-2} \mathrm{~S}-$ loaded cathode implemented with the DMTA-COF/ceramic separator at $0.5 \mathrm{C}$ and (f) at 2C. Reprinted with permission from ref. 116. Copyright 2018 American Chemical Society.

that of all the other reported related batteries with a lifetime of 600 h over 3600 cycles (Fig. 13f). These results indicate the great potency of hexaiminobenzene MOFs along with membranes made of superionic bio-cellulose for the subsequent design of commercial rechargeable $\mathrm{Zn}$-air batteries, as shown in Fig. $13 \mathrm{~g}-\mathrm{i}^{120}$

Bimetallic MOFs are also attractive as they can both act as ORR and OER catalysts. A bifunctional catalyst for both ORR and OER obtained from bimetallic MOF as palladium-induced $\mathrm{FeNi}_{3} \mathrm{C}_{x}$ nanorods have been reported by $\mathrm{T}$. Li et al. A large specific capacity of $772 \mathrm{~mA} \mathrm{~h} \mathrm{~g}^{-1}$ and energy density of $\sim 967 \mathrm{~W} \mathrm{~h} \mathrm{~kg}^{-1}$ was reported for the concerned $\mathrm{Zn}$-air battery associated with the $\mathrm{FeNi}_{3} \mathrm{C}_{x}$-Pd-7\% bifunctional catalyst. Interestingly, these values were much higher as compared to that of the $\mathrm{Pt} / \mathrm{C}+\mathrm{RuO}_{2}$ aircathode-associated $\mathrm{Zn}$-air batteries with a specific capacity of $624 \mathrm{~mA} \mathrm{~h} \mathrm{~g}^{-1}$ and an energy density of $\sim 776 \mathrm{~W} \mathrm{~h} \mathrm{~kg}^{-1}$. The full cycle cell efficiency was reported to be $62.6 \%$ for over150 h. ${ }^{121}$ However, for pristine MOFs, the problem of lesser conductivity sometimes may prove to deteriorate the performance of the aircathode. To mitigate the problem, MOFs have been encapsulated within the conductive framework in order to increase the conductivity. Nanoarrays of Co-based MOF framed within threedimensional graphite have also been used as a bifunctional catalyst, as reported by G. Chen et al. The as-designed Zn-air battery could deliver a peak power density of $86.2 \mathrm{~mW} \mathrm{~cm}^{-2}$ with appreciable stability. ${ }^{122}$ A similar instance of incorporating ZIF-67 MOF ( $<100 \mathrm{~nm}$ ) within hollow mesoporous carbon spheres (HMCS) (ZIF@HMCS-25\%) to generate yolk-shell structures with better conductivity (ion and electron) can be seen in a report by W. Xiong et al. The spatial confinement led to the desired size control of the MOFs and limited it to strictly $<100 \mathrm{~nm}$. The spatial 
(a)

(d)
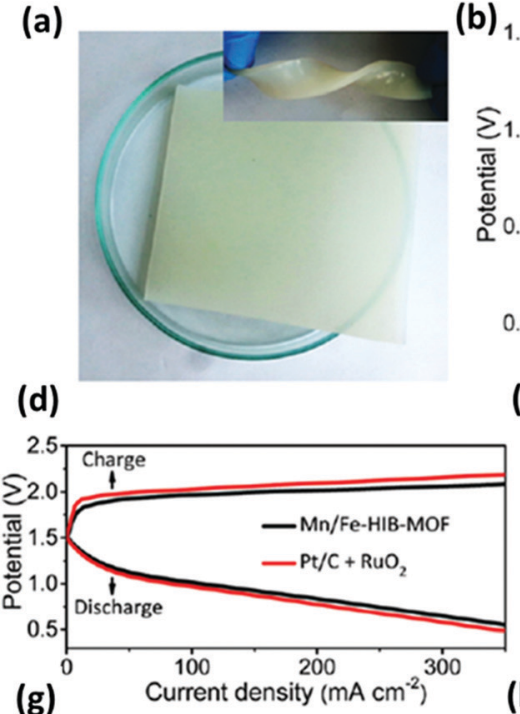

(g)

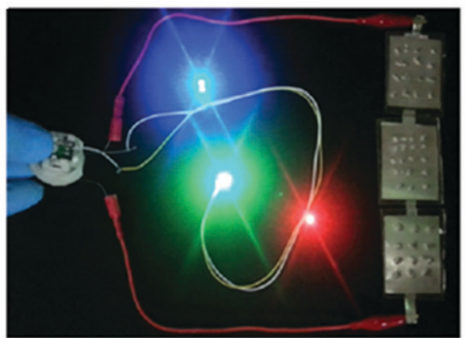

(b)



(e)



(h)



(c)

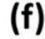

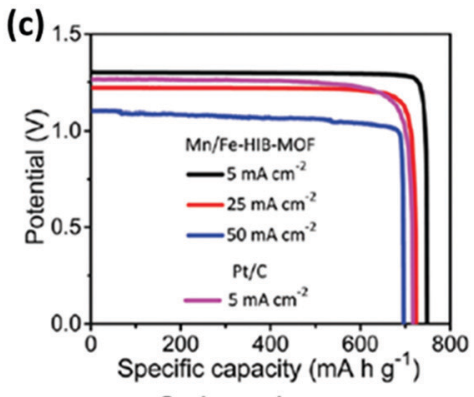

Cycle number

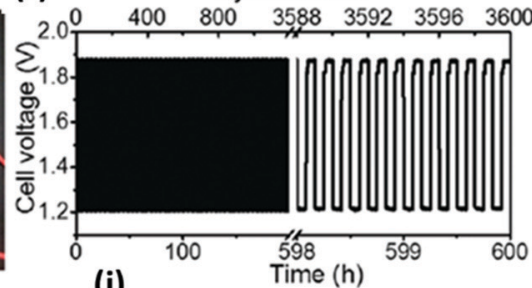

(i)

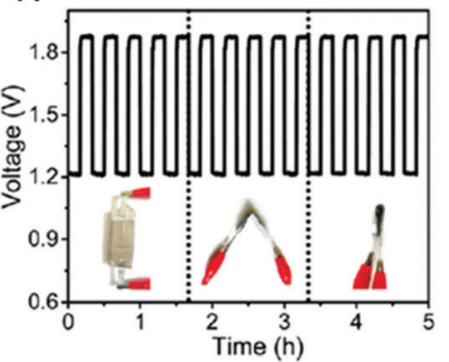

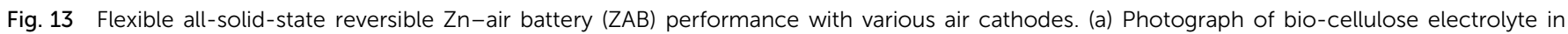

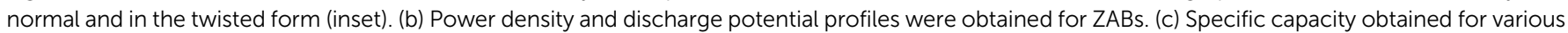

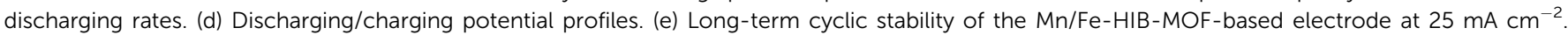

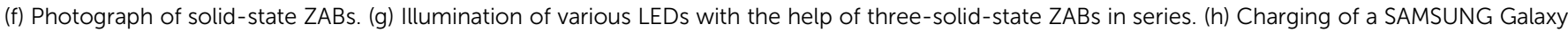


Reprinted with permission from ref. 120. Copyright 2018 Royal Society of Chemistry.

confinement also resulted in an enhancement in the electrical conductivity of the system. The obtained ZIF@HMCS-25\% hybrid material exhibits a highly efficient ORR activity with $0.823 \mathrm{~V}$ (vs. RHE) half-wave potential and an even higher kinetic current density $\left(J_{\mathrm{k}}=13.8 \mathrm{~mA} \mathrm{~cm}{ }^{-2}\right)$ than that of commercial $\mathrm{Pt} / \mathrm{C}$. ZIF@HMCS-25\% also displays excellent OER performance and the overpotential of ZIF@HMCS-25\% at $10 \mathrm{~mA} \mathrm{~cm}^{-2}$ is $407 \mathrm{mV}$. The ZIF@HMCS-25\% air-cathode-incorporated rechargeable Zn-air battery further exhibited a high power density of $120.2 \mathrm{~mW} \mathrm{~cm} \mathrm{~cm}^{-2}$ along with a long cycle life of $80 \mathrm{~h}$. Such a design is quite interesting and indicates the effectiveness of MOF confinement for yielding size-controlled structures and enhanced electrical conductivity. ${ }^{123}$ In a similar report by X. Wu et al., porous carbon polyhedra obtained from Zn-doped Co-based zeolitic imidazolate frameworks (ZnCo-ZIFs) were demonstrated to function as a bifunctional catalyst. Interestingly, the primary and rechargeable zinc-air batteries associated with these air-cathodes with optimal porous carbon polyhedra exhibited better performance as compared to $\mathrm{Pt} / \mathrm{C}$ catalysts. ${ }^{124}$

MOFs have also been reported not only as a bifunctional catalyst but also as trifunctional catalysts in some reports where they have been used in complete water splitting as well as ORR and OER reactions. As reported by T. Meng, selenized zeolitic imidazolate framework-67 (ZIF-67) polyhedron has been used to obtain coupled ultrafine $\mathrm{Co}_{0.85}$ Se nanocrystals and N-doped carbon (NC) ( $\left.\mathrm{Co}_{0.85} \mathrm{Se} @ \mathrm{NC}\right)$ as a trifunctional catalyst (Fig. 14a-c). The corresponding Zn-air battery exhibited a small dischargecharge voltage gap with high stability (180 cycles) (Fig. 14d). These results indicated the possibly improved catalytic activity from $\mathrm{Co}_{0.85} \mathrm{Se} @ \mathrm{NC}$ for clean and green energy systems. ${ }^{25}$

Another instance of the synergy between heteroatoms in improving the electrocatalytic activity for $\mathrm{Zn}$-air battery can be seen in a report by $\mathrm{Z}$. Li et al. This group obtained an ORR electrocatalyst based on a covalent organic framework consisting of hexachlorocyclotriphosphazene and dicyanamide coated on carbon nanotube via thermal polymerization. When used in a Zn-air battery as an air-electrode, the battery achieved a large open-circuit potential of $1.53 \mathrm{~V}$ and a maximum power density corresponding to $0.255 \mathrm{~W} \mathrm{~cm}^{-2} \cdot{ }^{125}$ Several reports are available where MOF-based electrocatalysts have been used for $\mathrm{Na}-\mathrm{O}_{2}$, $\mathrm{Al}-\mathrm{O}_{2}$ batteries and are also demonstrated to be incorporated into MOF-based electrocatalysts. In a report by Y. Liu, zeolitic imidazolate framework (ZIF-67)/RGO, (GO)/zinc nitrate derived reduced graphene oxide (rGO)-supported hollow $\mathrm{ZnO} / \mathrm{ZnCo}_{2} \mathrm{O}_{4}$ 
(a)

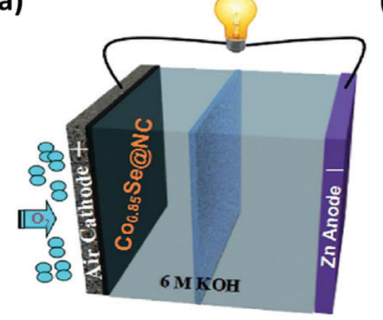

(c)

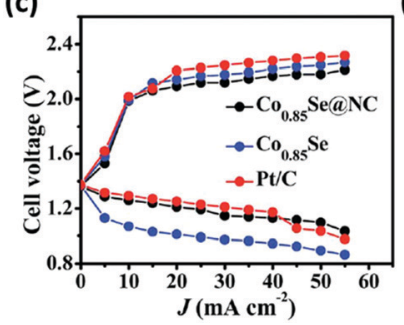

(b)

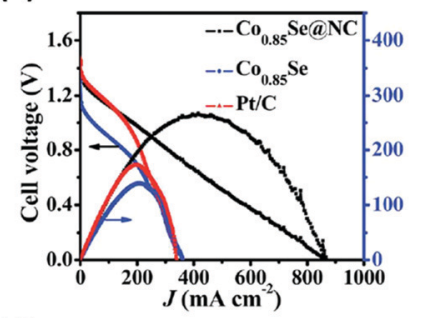

(d)

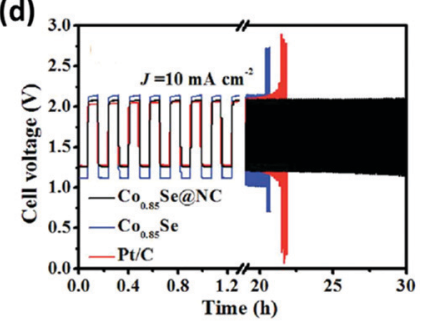

Fig. 14 Electrochemical performance of the $\mathrm{CO}_{0.85} \mathrm{Se}$ aNC cathode incorporated Zn-air battery: (a) Schematic representation of rechargeable Zn-air battery. (b) Polarization plot $(V-i)$ and associated power density plot. (c) Charge/discharge potential $(V-i)$ plots. (d) Cyclic stability performance. Reprinted with permission. ${ }^{25}$ Copyright 2017 Royal Society of Chemistry.

nanoparticle-incorporated carbon nanocages $\left(\mathrm{ZnO} / \mathrm{ZnCo}_{2} \mathrm{O}_{4} /\right.$ C@rGO), when implemented in Al-air coin cells as cathode catalysts, displayed a larger open-circuit voltage and higher discharge voltage and more sluggish potential drop as compared to the air cathode without rGO incorporation. ${ }^{126}$ MOF-derived materials have also been implemented in $\mathrm{Na}^{-} \mathrm{O}_{2}$ batteries; herein, we include some examples of such systems. Y. Wu et al. have reported the synthesis of MOF-derived N-doped carbon nanotubes (MOF-NCNTs) for hybrid Na-air batteries, which exhibited the lowest voltage gap of $0.30 \mathrm{~V}$ at $0.1 \mathrm{~mA} \mathrm{~cm}{ }^{-2}$, lowest compared to even commercial Pt/C $(0.50 \mathrm{~V})$. Further, the battery exhibited fair cyclic stability with an efficiency of $87 \%$ for the first 35 cycles at $0.1 \mathrm{~mA} \mathrm{~cm}{ }^{-2} \cdot{ }^{60}$ In a report by M. Abirami et al., cobalt manganese oxide (CMO) nanocubes effectively acted as a cathode electrocatalyst with an open cathode and seawater electrolyte in a rechargeable hybrid type Na-air battery. The concerned battery incorporated with the CMO bifunctional catalyst exhibited a voltage gap of $\sim 0.53 \mathrm{~V}$. When hard carbon anode was used as the Na-metal-free electrode with seawater as the electrolyte, the resulting battery exhibited a good cyclic life with a discharge voltage of $\sim 2.7 \mathrm{~V}$ and a capacity of $\sim 190 \mathrm{~mA} \mathrm{~h} \mathrm{~g}{ }^{-1}$ for the first 100 cycles. The energy efficiency for such a hybrid battery was as high as $74-79 \% .{ }^{127}$ A comparative study for all the previously mentioned trifunctional and bifunctional MOF-based catalysts is listed in Table $1 .^{26,120-122,124-127}$

\section{MOF as cathode materials for various energy storage modes}

Apart from being used as the anode, designing cheaper and novel cathode materials should be considered as a crucial step

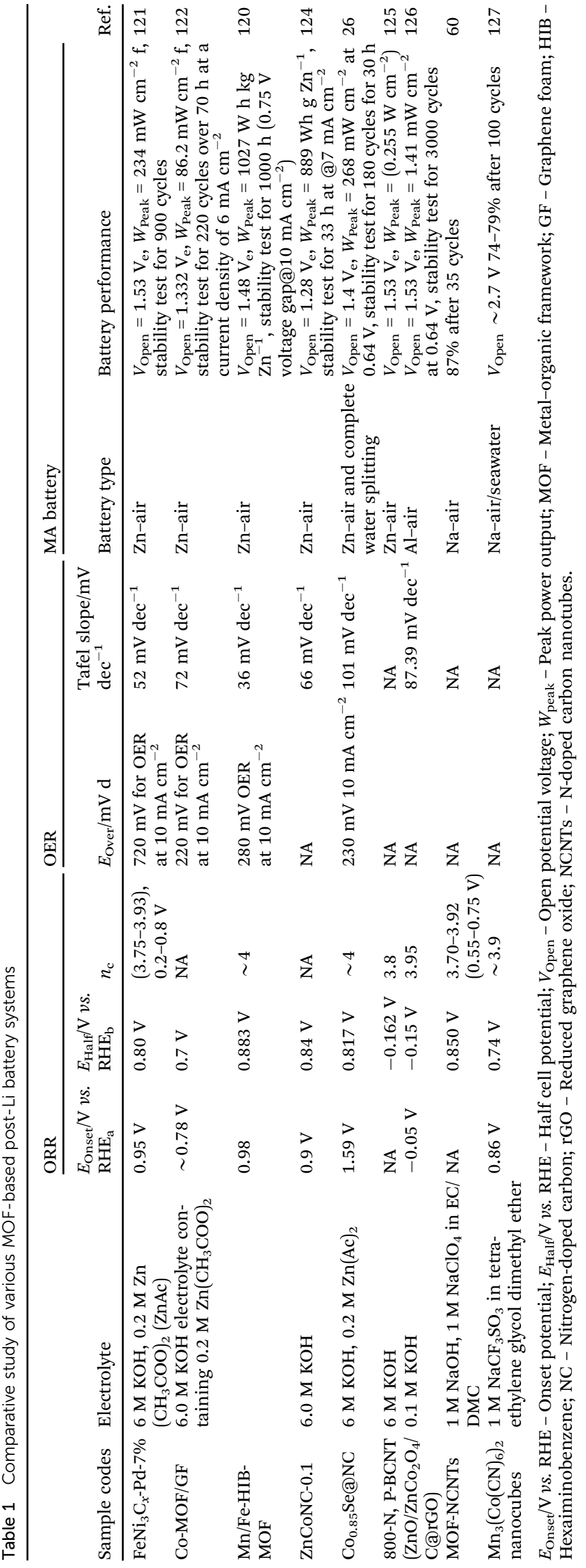


for cost reduction because the cathode materials comprise over $40 \%$ of the overall cost of LIBs. In the pursuit of better and novel cathode materials, the attention has been shifted from the available conventional cathode materials to unconventional electrode materials including MOFs $^{128-131}$ and organic compounds. ${ }^{132-135}$ Many MOFs have been reported so far as Li-cathodes. ${ }^{55,136,137}$ Similar Li-based battery MOFs have been reported in non-Lithium batteries too. For instance, in our previous work, we investigated Metal Organo-Phosphate Open Frameworks (MOPOFs) as cathode materials for Li-ion batteries. ${ }^{55,138}$ These frameworks, $\mathrm{A}_{2}-\left((\mathrm{VO})_{2}\left(\mathrm{HPO}_{4}\right)_{2}\left(\mathrm{C}_{2} \mathrm{O}_{4}\right)\right) ; \mathrm{A}=$ $\mathrm{Li}, \mathrm{Na}$, and $\mathrm{K}$, consist of layered structures and alkali metal cations are present and reversibly stored in the inter-layer space. The material showed good lithium storage capacity at a potential of $\sim 4 \mathrm{~V}$ and the observed voltage was higher than that of the $\mathrm{LiFePO}_{4}(3.5 \mathrm{~V} v$ s. Li) cathode, which was associated with reasonably fair theoretical capacities of $108-125 \mathrm{~mA} \mathrm{~h} \mathrm{~g}^{-1}$ (Fig. 15a-d). The fascinating lithium storage characteristics of these MOPOFs has inspired the pursuit of a family of alternate hybrid cathode materials comprising of a phosphate group. ${ }^{137}$ Recently, it has also been reported that $\mathrm{A}_{2}(\mathrm{~A}=\mathrm{Li}, \mathrm{Na}$, and $\mathrm{K})$ can act as cathode materials for Li-ion battery application. ${ }^{136}$ Further improvement in the capacity is possible by optimizing the synthesis and design of low molecular weight MOPOFs. The hydrated phases, $\mathrm{Na}_{2.2} \mathrm{H}_{2} \mathrm{O}$ and $\mathrm{K}_{2.3} \mathrm{H}_{2} \mathrm{O}$, were synthesized as single crystals using the hydrothermal method and their chemical structures were observed by single-crystal X-ray diffraction analyses. ${ }^{136}$ The electrochemical study of the anhydrous oxalatophosphites, $\mathrm{A}_{2} ;{ }^{136} \mathrm{~A}=\mathrm{Li}, \mathrm{Na}$, and $\mathrm{K}$, revealed the reversible intercalation of $\mathrm{Li}$ in these materials at $\sim 3.8 \mathrm{~V}$. Besides the use of MOFs in Li-based rechargeable batteries, their use as cathode materials in non-lithium batteries has also been recently reported. ${ }^{137}$
Sodium-ion batteries are striking alternatives to lithium-ion batteries due to the cost-effectiveness and abundance of sodium. Iron difluoride $\left(\mathrm{FeF}_{2}\right)$ is a conversion-based cathode material, in which energy storage is almost unlikely to be affected due to the large size of the $\mathrm{Na}^{+}$ion. It is also wellknown for its large theoretical capacity of $571 \mathrm{~mA} \mathrm{~h} \mathrm{~g} \mathrm{~g}^{-1}$. However, the low electrical conductivity of $\mathrm{FeF}_{2}$ leads to the rapid fading of the reversible capacity and cycle life of SIBs. The material of the study consisted of $\mathrm{FeF}_{2}$ nanoparticles entrenched into graphitic carbon $\left(\mathrm{FeF}_{2} @ \mathrm{GC}\right) . \mathrm{FeF}_{2} @ \mathrm{GC}$ was synthesized from Fe-MIL-88B MOF. By investigating the structural alterations of bare $\mathrm{FeF}_{2}$ during cycling, it was observed that the in situ phase transformation of $\mathrm{FeF}_{2}$ into $\mathrm{FeF}_{3}$ is a prerequisite to obtain excellent cycling performance. FeF $_{2}$ @GC exhibited augmented cycling stability, associated with a reversible capacity of $120.5 \mathrm{~mA} \mathrm{~h} \mathrm{~g}^{-1}$ over 300 cycles at $50 \mathrm{~mA} \mathrm{~g}^{-1} .^{139}$ The performance of some more MOF-based cathodes for $\mathrm{Na}$-ion battery has been listed in Table $2 .^{83,95,96,140-146}$

As reported by Goodenough and co-workers, Prussian blue $\mathrm{KFeFe}(\mathrm{CN})_{6}$ was observed to be quite stable, possessing an open framework in carbonate electrolyte during $\mathrm{Na}^{+}$insertion/ de-insertion. ${ }^{96}$

Fig. 16a represents the voltage profiles of the sodium manganese hexacyanoferrate/Na (NMHFC/Na) half-cells. NMHFC-1 showed a discharge capacity as high as $130 \mathrm{~mA} \mathrm{~h} \mathrm{~g}^{-1}$, retaining $121 \mathrm{~mA} \mathrm{~h} \mathrm{~g}^{-1}$ over 30 cycles at 1/20C. Meanwhile, NMHFC-2 showed stable capacity with very little capacity fading and $96 \%$ capacity retention over 30 cycles. The capacity fading was ascribed to the phase transition during $\mathrm{Na}^{+}$insertion/de-insertion. Nevertheless, NMHFC with a stable reversible capacity of more than $120 \mathrm{~mA} \mathrm{~h} \mathrm{~g}^{-1}$ and a high voltage of $3.4 \mathrm{~V}$ is a promising cathode in SIBs. Fig. 16b shows the discharge profiles of NMHFC-1 at varying current densities, showing the excellent rate capability of this electrode material. Also,
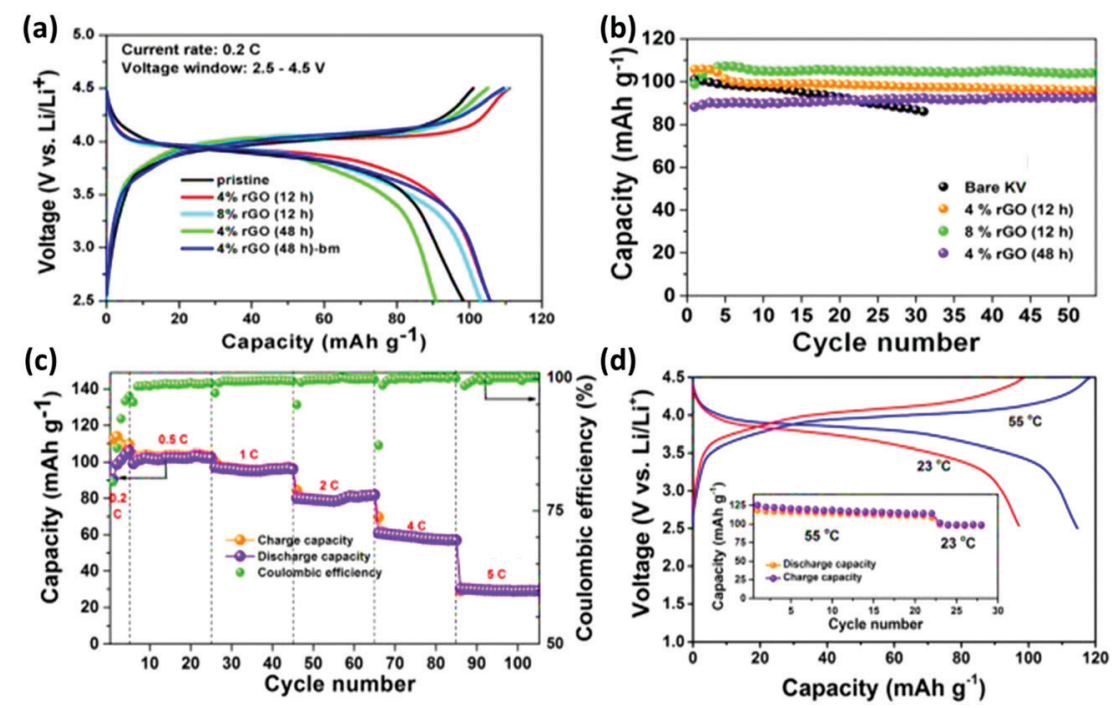

Fig. 15 (a) Voltage vs. capacity plots of $\mathrm{rGO}$ and different $\mathrm{rGO}$ nanocomposites at $20 \mathrm{~mA} \mathrm{~g}^{-1}$ ( $\sim 0.2 \mathrm{C}$ current rate); (b) cyclic stability measurement plots for $\mathrm{rGO}$ and $\mathrm{rGO}$ nanocomposites at $20 \mathrm{~mA} \mathrm{~g}^{-1}$ ( $\sim 0.2 \mathrm{C}$ current rate); (c) rate capability analysis of bm-rGO/ $\mathrm{K}_{2}$ (with $4 \% \mathrm{rGO}$ ) with varying current rates of $0.2,0.5,1,2,4$, and $5 \mathrm{C}$, when $1 \mathrm{C}$ is equal to a current density of $108 \mathrm{~mA} \mathrm{~g}^{-1}$, and (d) charge/discharge plots of bm-rGO/ $\mathrm{K}_{2}\left((\mathrm{VO})_{2}(\mathrm{HPO})_{2}\left(\mathrm{C}_{2} \mathrm{O}_{4}\right)\right)($ with $4 \% \mathrm{rGO}$ ) at an elevated temperature of $55^{\circ} \mathrm{C}$ at $20 \mathrm{~mA} \mathrm{~g}^{-1}\left(\sim 0.2 \mathrm{C}\right.$ current rate). Cyclic stability plots at $55^{\circ} \mathrm{C}$ (inset). Reproduced from ref. 136 . 
Table 2 Previously reported performance of MOF-based materials as cathode materials for SIBs

\begin{tabular}{|c|c|c|c|c|c|}
\hline Material & Type of battery & $\begin{array}{l}\text { Operating } \\
\text { potential (V) }\end{array}$ & Rate capability (high) (mA h g $\left.{ }^{-1}\right)$ & Rate capability (low) (mA h g $\left.{ }^{-1}\right)$ & Ref. \\
\hline $\mathrm{KCoFe}(\mathrm{CN})_{6}$ & Na-ion & $2.0-4.0$ & - & $\sim 55$ at $0.05 \mathrm{C}$ & 95 \\
\hline $\mathrm{KNiFe}(\mathrm{CN})_{6}$ & Na-ion & $2.0-4.0$ & - & $\sim 55$ at $0.05 \mathrm{C}$ & 95 \\
\hline $\mathrm{KZnFe}(\mathrm{CN})_{6}$ & Na-ion & $2.0-4.0$ & - & $\sim 55$ at $0.05 \mathrm{C}$ & 95 \\
\hline $\mathrm{FeFe}(\mathrm{CN}) 6$ & Na-ion & $2.0-4.0$ & 98 at $10 \mathrm{C}, 67$ after 500 cycles at $20 \mathrm{C}$ & 120 at $0.5 \mathrm{C}$ & 140 \\
\hline $\mathrm{Na}_{1.72} \mathrm{MnFe}(\mathrm{CN})_{6}$ & Na-ion & $2.0-4.2$ & 45 at $40 \mathrm{C}$ & 121 after 30 cycles at $0.05 \mathrm{C}$ & 96 \\
\hline $\mathrm{Na}_{0.61} \mathrm{Fe}\left(\mathrm{Fe}(\mathrm{CN})_{6}\right)_{0.94}$ & Na-ion & $2.0-4.2$ & 170 after 150 cycles at $25 \mathrm{~mA} \mathrm{~g}^{-1}$ & $\begin{array}{l}110 \text { at } 150 \mathrm{~mA} \mathrm{~g}^{-1}, 70 \text { at } \\
600 \mathrm{~mA} \mathrm{~g}^{-1}\end{array}$ & 143 \\
\hline $\mathrm{Na}_{3,27} \mathrm{Fe}_{0.35} \cdot 0.85 \mathrm{H}_{2} \mathrm{O}$ & Na-ion & $2.0-4.5$ & 70 after 100 cycles $0.89 \mathrm{C}$ & 103 at $0.22 \mathrm{C}$ & 143 \\
\hline $\mathrm{R}-\mathrm{Na}_{1.92} \mathrm{Fe}$ & Na-ion & $2.0-4.0$ & 120 after 1000 cycles at $300 \mathrm{~mA} \mathrm{~g}^{-1}$ & 160 at $10 \mathrm{~mA} \mathrm{~g}^{-1}$ & 145 \\
\hline $\mathrm{Na}_{2} \mathrm{Mn}_{0.15} \mathrm{Co}_{0.15} \mathrm{Ni}_{0.1} \mathrm{Fe}_{0.6} \mathrm{Fe}(\mathrm{CN})_{6}$ & Na-ion & $2.0-4.0$ & 87.4 after 1500 cycles at $1 \mathrm{C}$ & 117 at $0.1 \mathrm{C}$ & 146 \\
\hline
\end{tabular}

as can be seen in Fig. 16c, the variation in the discharge capacity and Coulombic efficiency is quite impressive for this material. Further, the rate capability is anticipated to improve on compositing this material with other conductive materials such as carbon. Even though the specific capacity of NMHFC is lesser than that of LIB cathodes including $\mathrm{LiCoO}_{2}, \mathrm{LiFePO}_{4}$, and $\mathrm{LiNi}_{1} / 3 \mathrm{Co}_{1} / 3 \mathrm{Mn}_{1} /$ $3 \mathrm{O}_{2}$, its better rate capability confirms the delivery of large power density, which is necessary for power tools and stationary energy storage. $^{96}$

Selenium cathodes have garnered significant attention due to their much larger electronic conductivity and analogous volumetric capacity when compared with sulfur cathodes. Nevertheless, selenium cathodes are challenged by their large volume changes, low utilization of active materials, and the shuttle effect of polyselenides, as discussed earlier, leading to fast capacity fading. Yu and co-workers reported selenium-carbon composites as cathode materials for sodium-selenium batteries for improving the use of selenium by implanting selenium in ZIF8-derived microporous $\mathrm{N}$-doped carbon polyhedra (denoted as Se@N-MCPs). The N-MCPs could significantly accommodate the volume alteration of Se@N-MCPs and augment the shuttle effect of polyselenides. The Se@N-MCP cathodes delivered a discharge capacity of $612 \mathrm{~mA} \mathrm{~h} \mathrm{~g}^{-1}$ after 100 cycles at $0.1 \mathrm{~A} \mathrm{~g}^{-1}$ and a better rate capability of $496 \mathrm{~mA} \mathrm{~h} \mathrm{~g}{ }^{-1}$ at $5 \mathrm{~A} \mathrm{~g}^{-1}$ for Na-Se batteries. Furthermore, they also exhibited a superior cycling life with only $0.049 \%$ capacity decline per cycle. ${ }^{147}$

MOFs with tunable structures and high surface areas have garnered attention as cathode materials of next-generation energy storage. However, directly adapting MOF as a binder-free cathode material remains a challenge due to their less conductivity.
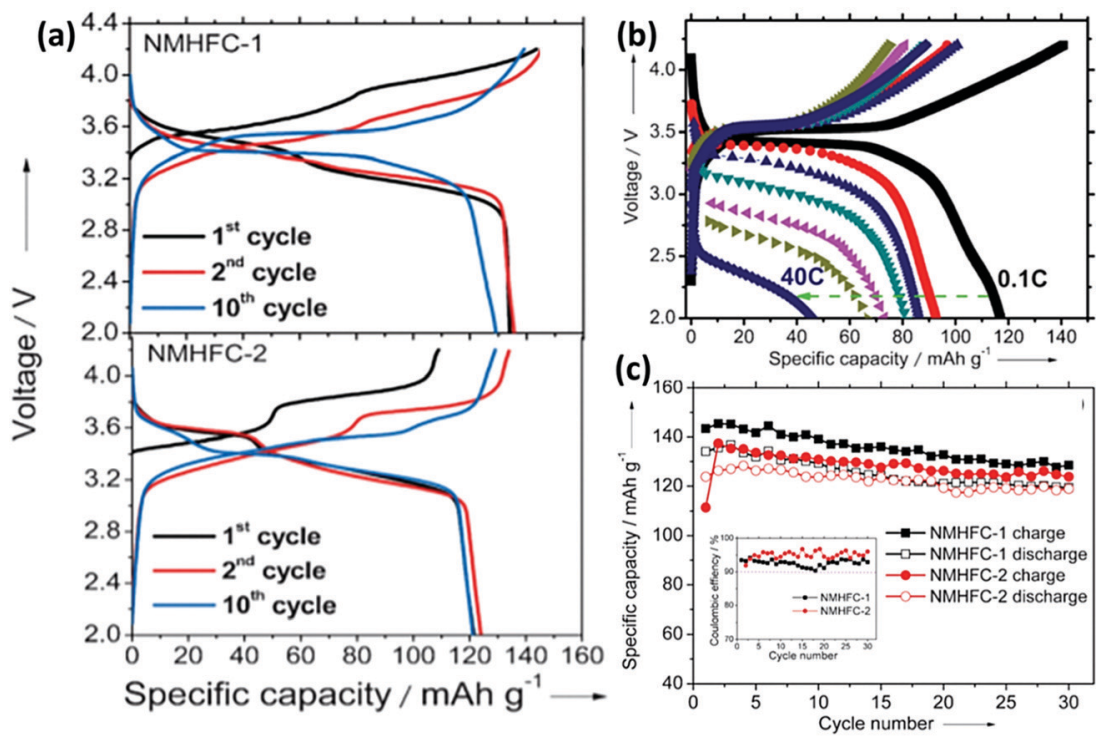

Fig. 16 (a) Potential profiles at various cycles of sodium manganese hexacyanoferrate/Na (NMHFCs/Na) half cells. (b) Charge/discharge profiles of an NMHFC-1/Na half-cell at several current densities when cycled for 30 cycles before the rate test between 2.0 and $4.2 \mathrm{~V}$ at $0.1 \mathrm{C}$. (c) Charge/discharge capacity and Coulombic efficiency (inset image) variation with cycle number when the cells were cycled between 2.0 and $4.2 \mathrm{~V}$ at $1 / 20 \mathrm{C}\left(120 \mathrm{~mA} \mathrm{~g} \mathrm{gat}^{-1} \mathrm{C}\right.$ ). Adapted from ref. 96 with permission. Copyright 2013 Wiley-VCH. 
Also, Yao and co-workers reported a self-sacrificed route to develop three-dimensional conducting vanadium-based MOFs (V-MOFs, MIL-47) arrays nanowire-bundle on fibers of carbon nanotubes as cathode material for Zn-ion batteries (aqueous). ${ }^{148}$ Due to their high conductivity, plentiful active sites, and hierarchical porosity, the assembled Zn-ion battery possessed a large volumetric capacity corresponding to the value of $102 \mathrm{~mA} \mathrm{~h} \mathrm{~cm}^{-3}$ at $0.1 \mathrm{~A} \mathrm{~cm}^{-3}$ and an outstanding rate capability of $64.3 \%$ for initial capacity retention after a 50-times increase in the current density measured in an aqueous electrolyte. Importantly, the designed all-solid-state fiber-shaped flexible Zn-ion battery synchronously exhibited a high energy density $\left(17.4 \mathrm{~mW} \mathrm{~h} \mathrm{~cm}^{-3}\right)$ as well as high power density $\left(1.46 \mathrm{~W} \mathrm{~cm}^{-3}\right)$. This work validates that the designed $\mathrm{V}$-MOF can act as a promising cathode material in $\mathrm{Zn}$-ion batteries, inspiring more works related to the growth of transition-metal-based conductive MOFs nanowires on current collectors for next-generation energy storage devices. ${ }^{148}$ Further, Xiehong Cao and co-workers reported a cathode material comprising of $\mathrm{MnO}_{2}$ nanosheet-based hollow polyhedron attached to carbon cloth $\left(\mathrm{MnO}_{2} / \mathrm{CC}\right)$. The electrode material was synthesized through a fast hydrothermal method implementing ZIF-67 as the self-sacrificing template. The $\mathrm{MnO}_{2} / \mathrm{CC}$ exhibited a large reversible capacity of $264 \mathrm{~mA} \mathrm{~h} \mathrm{~g}^{-1}$ at $1.0 \mathrm{~A} \mathrm{~g}^{-1}$ after 300 cycles. A flexible $\mathrm{Zn}$-ion battery comprising of $\mathrm{MnO}_{2} / \mathrm{CC}$ exhibited a stable output potential of $1.53 \mathrm{~V}$, which was associated with a specific capacity of $91.7 \mathrm{~mA} \mathrm{~h} \mathrm{~g}^{-1}$ retention of at $0.1 \mathrm{~A} \mathrm{~g}^{-1}$ after 30 cycles. ${ }^{149}$ A novel synthetic strategy was proposed by Xiehong Cao and co-workers for the fabrication of high-density and monolithic $\mathrm{NiS}_{2} /$ reduced graphene oxide $\left(\mathrm{NiS}_{2} / \mathrm{rGO}\right)$ composite cathode materials to attain high volumetric and gravimetric energy densities when tested for Ni-Zn batteries. The fabricated $\mathrm{Ni}-\mathrm{Zn}$ battery exhibits high volumetric energy density, reaching a value of $18.7 \mathrm{~mW} \mathrm{~h} \mathrm{~cm}{ }^{-3}$, which is associated with an energy density of $358 \mathrm{~W} \mathrm{~h} \mathrm{~kg}^{-1}$. This battery also exhibited outstanding longterm durability. ${ }^{150}$ A facile alkali-soaking strategy has been proposed for the facile synthesis of $2 \mathrm{D}$ transition metal hydroxide/oxide nanosheet-based hierarchical structures by annealing, followed by alkali soaking of bimetallic MOFs. Using this method of synthesis, various hierarchical structure scaffolds on 2D materials, such as $\mathrm{Ni}(\mathrm{OH})_{2}, \mathrm{Co}(\mathrm{OH})_{2}$, and $\mathrm{Mn}_{3} \mathrm{O}_{4}$ nanosheets, have been synthesized. When tested as the cathode for the $\mathrm{Zn}$ air battery, the device delivered a truncated charging/discharging potential gap of $2.2 \mathrm{~V}$ at $75 \mathrm{~mA} \mathrm{~cm}{ }^{-2}$ and stability over $240 \mathrm{~h}^{151}$ Further, electrochemical energy storage systems for capacitive deionization were established as an energy-efficient and costeffective technology for water desalination. A recent work has implemented a novel tubular-structured electrode comprising of Prussian blue nanocrystals-embedded polyaniline (PANI)-tube (PB/PANI composite). Benefiting from the rationally designed composition and unique structure, the obtained $\mathrm{PB} / \mathrm{PANI}$ exhibits a large desalination capacity, reaching a value of $133.3 \mathrm{mg} \mathrm{g}^{-1}$ at $100 \mathrm{~mA} \mathrm{~g}^{-1}$, and an excellent salt-removal rate of $0.49 \mathrm{mg} \mathrm{g}^{-1} \mathrm{~s}^{-1}$ at $2 \mathrm{~A} \mathrm{~g}^{-1}$. This work demonstrates a facile approach for designing PB-based composites, thus motivating the progress of advanced materials for high-performance capacitive deionization applications. ${ }^{152}$

\section{Conclusion and future perspectives}

Modern-day research has well recognized the potential of Li-ion battery systems and it is believed that the research on Li-ion batteries has reached saturation. In the pursuit of improved charge storage modes, batteries employing conversion mechanism such as MA and MS batteries have gained much interest. Also, a desperate need to replace Li metal in these battery systems has directed battery research to shift towards other naturally abundant metals including $\mathrm{Na}, \mathrm{Mg}, \mathrm{Ca}$, and $\mathrm{K}$. However, these systems face several problems concerned with safety and device performance. A detailed discussion has been included in this review with the possible approaches to mitigate the problems. This review specifically outlines the utility of metal-organic frameworks (MOFs) in non-lithium MI, MS, and MA batteries. For pure MOFs, the largely ordered arrangements of atoms and regular pore features offer great opportunities to relate the structure-composition-performance relations and attain ideal active sites with large abundance and large activity synchronously. Due to the widespread compositional and structural diversity of MOFs, architecting the metal centers and organic linkers can significantly modulate the performance of pristine MOFs. The creation of defects or nano-fabrication of MOFs having a large surface to volume ratios can significantly enhance the number of active sites in MOFs. Some effective strategies to optimize the activity of pure MOFs include the induction of multiple valence metal sites and heterometallic doping, the introduction of functional groups into organic linkers, adsorption of different kinds of ions on the organic linkers/metal nodes, and encapsulation of conjugated organic linkers in the skeletons. These architecting strategies are captivating to tune the charge transfer channels, electronic structures, bonding energy of intermediates, photoresponse, conductivity, and structural stability of pure MOFs. A combination of functional components with MOFs to design MOF composites can efficiently overcome the disadvantages of individual components and possess multiple functionalities by the establishment of synergy with the host and guest. MOF derivatives have also garnered huge attention as a result of their significant stability and large activity for application in practical energy storage systems. MOFs have turned out to be useful not only as electrode materials but also as catalysts in MA batteries and sulfur hosts in MS batteries. The problem of polysulfide formation can be mitigated in MS batteries by employing MOFderived carbon as the sulfur host. MOF-derived carbons act as better sulfur hosts as they contain metal centers that can act as active binding sites for sulfur. Also, these MOFs can act as a multifunctional catalyst to enhance the charge storage properties in MA battery systems. MOFs show quite a huge potential to act as successful candidates for post-Li battery systems. The conversion of MOFs and MOF composites can result in the creation of metal compounds, MOF-derived carbon, and metal/ carbon hybrids. In addition to the design of the MOF-based component, it is also essential to engineer MOF-derived materials into $0 \mathrm{D}, 1 \mathrm{D}, 2 \mathrm{D}$, and 3D nanostructures exhibiting porous nature for energy storage systems. Advanced nanostructures can offer large structural strength in harsh conditions, easy accessibility of 
reactants to the active sites, and effective electron transport pathways. Thus, the careful design of advanced nanostructures is a crucial technique to extend the adaptability of MOF-based materials for energy storage systems.

In spite of the significant progress made so far on MOFbased materials for energy storage systems, several challenges remain to be addressed. The poor stability of pure MOFs and MOF-based composites is required to be overcome to meet the necessities in practical energy storage devices, especially electrochemical energy storage devices, where punitive potentials and electrolytes are applied. For MOF-based composites, the investigation, tunability of the interactions, and synergistic effect developed between the MOFs and the introduced components remain a challenge. In the case of MOF-derived materials, the difficulty of the transformation approach from MOF precursors to MOF-derived materials constantly results in uncontrollable compositional and structural evolution away from the targeted structures and compositions. Even though there lies a large mist of challenges, with the advancement of more advanced characterization techniques and the fundamental in-depth understanding of the structure-performance relationship of MOF-based materials for the electrochemical energy storage processes, we believe that MOF-based materials possessing desirable electro/photochemical properties are possible for achieving for practical energy storage devices. Also, it is believed that a much better design of post-Li batteries is possible with substantial research in the future.

\section{Conflicts of interest}

There are no conflicts to declare.

\section{Acknowledgements}

AKT acknowledges Suncheon National University \& Yeungnam University, Republic of Korea for support realated to post doctoral research. MM acknowledges IIT (ISM), Dhanbad. SPP would like to acknowledge the financial support from Khalifa University through FSU-2018-29, and the Department of Education and Knowledge under "The ADEK Award for Research Excellence (AARE) 2018: AARE18-136”.

\section{References}

1 M. V. Reddy, A. Mauger, C. M. Julien, A. Paolella and K. Zaghib, Materials, 2020, 13, 1884.

2 R. J. Brodd, Synopsis of the Lithium-Ion Battery Markets, in Lithium-Ion Batteries: Science and Technologies, ed. M. Yoshio, R. J. Brodd and A. Kozawa, Springer New York, New York, NY, 2009, pp. 1-7.

3 M. Majumder, M. S. Santosh, R. Viswanatha, A. K. Thakur, D. P. Dubal and K. Jayaramulu, Energy Storage Mater., 2021, 37, 396-415.

4 Y. Liang, C.-Z. Zhao, H. Yuan, Y. Chen, W. Zhang, J.-Q. Huang, D. Yu, Y. Liu, M.-M. Titirici, Y.-L. Chueh, H. Yu and Q. Zhang, InfoMat, 2019, 1, 6-32.
5 B. L. Ellis and L. F. Nazar, Curr. Opin. Solid State Mater. Sci., 2012, 16, 168-177.

6 T. Famprikis, P. Canepa, J. A. Dawson, M. S. Islam and C. Masquelier, Nat. Mater., 2019, 1-14.

7 M. Reddy, G. R. Ballesteros-Garrido, J. Lacour and S. Caldarelli, Angew. Chem., Int. Ed., 2013, 125, 3337-3340.

8 X. Hong, J. Mei, L. Wen, Y. Tong, A. J. Vasileff, L. Wang, J. Liang, Z. Sun and S. X. Dou, Adv. Mater., 2019, 31, 1802822.

9 Y. Guo, Y. Zhu, C. Yuan and C. Wang, Mater. Lett., 2017, 199, 101-104.

10 Y. Wang, R. Chen, T. Chen, H. Lv, G. Zhu, L. Ma, C. Wang, Z. Jin and J. Liu, Energy Storage Mater., 2016, 4, 103-129.

11 A. El Kharbachi, O. Zavorotynska, M. Latroche, F. Cuevas, V. Yartys and M. Fichtner, J. Alloys Compd., 2020, 817, 153261.

12 M. Majumder, R. B. Choudhary, A. K. Thakur and I. Karbhal, $R S C$ Adv., 2017, 7, 20037-20048.

13 M. Majumder, R. B. Choudhary, S. P. Koiry, A. K. Thakur and U. Kumar, Electrochim. Acta, 2017, 248, 98-111.

14 M. Majumder, R. B. Choudhary, A. K. Thakur and U. Kumar, J. Electroanal. Chem., 2017, 804, 42-52.

15 A. K. Thakur, A. B. Deshmukh, R. B. Choudhary, I. Karbhal, M. Majumder and M. V. Shelke, Mater. Sci. Eng., B, 2017, 223, 24-34.

16 A. K. Thakur, R. B. Choudhary, M. Majumder, G. Gupta and M. V. Shelke, J. Electroanal. Chem., 2016, 782, 278-287.

17 A. K. Thakur, R. B. Choudhary, M. Majumder and M. Majhi, Ionics, 2018, 24, 257-268.

18 M. Majumder, R. B. Choudhary, A. K. Thakur, C. S. Rout and G. Gupta, New J. Chem., 2018, 42, 5295-5308.

19 A. K. Thakur, M. Majumder, R. B. Choudhary and S. B. Singh, J. Power Sources, 2018, 402, 163-173.

20 M. Majumder, R. B. Choudhary and A. K. Thakur, Carbon, 2019, 142, 650-661.

21 R. B. Choudhary, M. Majumder and A. K. Thakur, ChemistrySelect, 2019, 4, 6906-6912.

22 M. Majumder, R. B. Choudhary, A. K. Thakur, A. Khodayari, M. Amiri, R. Boukherroub and S. Szunerits, Electrochim. Acta, 2020, 136609.

23 A. K. Thakur, M. Majumder and S. B. Singh, Graphene and Its Derivatives for Secondary Battery Application, in Surface Engineering of Graphene, ed. S. Sahoo, S. K. Tiwari and G. C. Nayak, Springer International Publishing, Cham, 2019, pp. 53-80.

24 M. Majumder and A. K. Thakur, Graphene and Its Modifications for Supercapacitor Applications, in Surface Engineering of Graphene, ed. S. Sahoo, S. K. Tiwari and G. C. Nayak, Springer International Publishing, Cham, 2019, pp. 113138.

25 T. Meng, J. Qin, S. Wang, D. Zhao, B. Mao and M. Cao, J. Mater. Chem. A, 2017, 5, 7001-7014.

26 X. Ge, Z. Li and L. Yin, Nano Energy, 2017, 32, 117-124.

27 K. Xi, S. Cao, X. Peng, C. Ducati, R. Vasant Kumar and A. K. Cheetham, Chem. Commun., 2013, 49, 2192-2194.

28 R. Zhao, Z. Liang, R. Zou and Q. Xu, Joule, 2018, 2, 2235-2259.

29 B. F. Hoskins and R. Robson, J. Am. Chem. Soc., 1989, 111, 5962-5964. 
30 B. F. Hoskins and R. Robson, J. Am. Chem. Soc., 1990, 112, 1546-1554.

31 O. M. Yaghi, G. Li and H. Li, Nature, 1995, 378, 703-706.

32 D. Venkataraman, G. B. Gardner, S. Lee and J. S. Moore, J. Am. Chem. Soc., 1995, 117, 11600-11601.

33 S. Subramanian and M. J. Zaworotko, Angew. Chem., Int. Ed. Engl., 1995, 34, 2127-2129.

34 K. Biradha, A. Ramanan and J. J. Vittal, Cryst. Growth Des., 2009, 9, 2969-2970.

35 W. L. Leong and J. J. Vittal, Chem. Rev., 2011, 111, 688-764.

36 H.-S. Lu, L. Bai, W.-W. Xiong, P. Li, J. Ding, G. Zhang, T. Wu, Y. Zhao, J.-M. Lee and Y. Yang, Inorg. Chem., 2014, 53, 8529-8537.

37 S. Li and F. Huo, Nanoscale, 2015, 7, 7482-7501.

38 Q. Qu, J. Yun, Z. Wan, H. Zheng, T. Gao, M. Shen, J. Shao and H. Zheng, RSC Adv., 2014, 4, 64692-64697.

39 G. Zou, H. Hou, X. Cao, P. Ge, G. Zhao, D. Yin and X. Ji, J. Mater. Chem. A, 2017, 5, 23550-23558.

40 X. Gu, P. Dai, L. Li, J. Li, D. Li, H. Zhang and X. Zhao, ChemistrySelect, 2016, 1, 6442-6447.

41 X. Gao, G. Zhu, X. Zhang and T. Hu, Microporous Mesoporous Mater., 2019, 273, 156-162.

42 B. Liu, H. Shioyama, T. Akita and Q. Xu, J. Am. Chem. Soc., 2008, 130, 5390-5391.

43 J. Hu, H. Wang, Q. Gao and H. Guo, Carbon, 2010, 48, 3599-3606.

44 G. Yilmaz, S. B. Peh, D. Zhao and G. W. Ho, Adv. Sci., 2019, 6, 1901129.

45 A. Mauger, C. M. Julien, A. Paolella, M. Armand and K. Zaghib, Materials, 2019, 12, 3892.

46 J. B. Goodenough, Acc. Chem. Res., 2013, 46, 1053-1061.

47 C. M. Julien and A. Mauger, Coatings, 2019, 9, 386.

48 J. Asenbauer, T. Eisenmann, M. Kuenzel, A. Kazzazi, Z. Chen and D. Bresser, Sustainable Energy Fuels, 2020, 4, 5387-5416.

49 T. F. Yi, L. J. Jiang, J. Shu, C. B. Yue, R. S. Zhu and H. B. Qiao, J. Phys. Chem. Solids, 2010, 71, 1236-1242.

50 B. Chen, Z. Huang, X. Chen, Y. Zhao, Q. Xu, P. Long, S. Chen and X. Xu, Electrochim. Acta, 2016, 210, 905-914.

51 M. Otoyama, Y. Ito, A. Hayashi and M. Tatsumisago, J. Power Sources, 2016, 302, 419-425.

52 D. H. S. Tan, E. A. Wu, H. Nguyen, Z. Chen, M. A. T. Marple, J.-M. Doux, X. Wang, H. Yang, A. Banerjee and Y. S. Meng, ACS Energy Lett., 2019, 4, 2418-2427.

53 A. Fedorková, A. Nacher-Alejos, P. Gómez-Romero, R. Oriňáková and D. Kaniansky, Electrochim. Acta, 2010, 55, 943-947.

54 M. Nagarathinam, K. Saravanan, E. J. H. Phua, M. V. Reddy, B. V. R. Chowdari and J. J. Vittal, Angew. Chem., Int. Ed., 2012, 51, 5866-5870.

55 X.-R. Zeng, W.-W. Jin, H.-J. Li, S. Inguva, Q. Zhang, S.-Z. Zeng, G.-Z. Xu and J.-Z. Zou, Nanotechnology, 2020, 31, 155602.

56 D. Deng, Energy Sci. Eng., 2015, 3, 385-418.

57 F. Xiao, X. Yang, H. Wang, J. Xu, Y. Liu, D. Y. W. Yu and A. L. Rogach, Adv. Energy Mater., 2020, 10, 2000931.

58 X. Li, S. Zheng, L. Jin, Y. Li, P. Geng, H. Xue, H. Pang and Q. Xu, Adv. Energy Mater., 2018, 8, 1800716.
59 Y. Li and J. Lu, ACS Energy Lett., 2017, 2, 1370-1377.

60 Y. Wu, X. Qiu, F. Liang, Q. Zhang, A. Koo, Y. Dai, Y. Lei and X. Sun, Appl. Catal., B, 2019, 241, 407-414.

61 L. Zhang, W. Liu, W. Shi, X. Xu, J. Mao, P. Li, C. Ye, R. Yin, S. Ye and X. Liu, Chem. - Eur. J., 2018, 24, 13792-13799.

62 W. Liu, R. Yin, X. Xu, L. Zhang, W. Shi and X. Cao, Adv. Sci., 2019, 6, 1802373.

63 C. Chen, M. Wu, Z. Xu, T. Feng, J. Yang, Z. Chen, S. Wang and Y. Wang, J. Colloid Interface Sci., 2019, 538, 267-276.

64 N. Angulakshmi, Y. Zhou, S. Suriyakumar, R. B. Dhanalakshmi, M. Satishrajan, S. Alwarappan, M. H. Alkordi and A. M. Stephan, ACS Omega, 2020, 5, 7885-7894.

65 Y. Zhong, F. Lin, M. Wang, Y. Zhang, Q. Ma, J. Lin, Z. Feng and H. Wang, Adv. Funct. Mater., 2020, 30, 1907579.

66 K. Xi, B. Chen, H. Li, R. Xie, C. Gao, C. Zhang, R. V. Kumar and J. Robertson, Nano Energy, 2015, 12, 538-546.

67 C. J. Hart, M. Cuisinier, X. Liang, D. Kundu, A. Garsuch and L. F. Nazar, Chem. Commun., 2015, 51, 2308-2311.

68 H. Park and D. J. Siegel, Chem. Mater., 2017, 29, 4932-4939.

69 Y. Wang, Z. Zhang, M. Haibara, D. Sun, X. Ma, Y. Jin, H. Munakata and K. Kanamura, Electrochim. Acta, 2017, 255, 109-117.

70 R. Zhang, A. M. Esposito, E. S. Thornburg, X. Chen, X. Zhang, M. A. Philip, A. Magana and A. A. Gewirth, ACS Appl. Mater. Interfaces, 2020, 12, 29285-29295.

71 W. Zhong, X. Lv, Q. Chen, M. Ren, W. Liu, G. Li, J. Yu, M. Li, Y. Dai and L. Wang, ACS Appl. Mater. Interfaces, 2019, 11, 37850-37858.

72 J. Ren, Y. Huang, H. Zhu, B. Zhang, H. Zhu, S. Shen, G. Tan, F. Wu, H. He, S. Lan, X. Xia and Q. Liu, Carbon Energy, 2020, 2, 176-202.

73 J. Qian, Y. Li, M. Zhang, R. Luo, F. Wang, Y. Ye, Y. Xing, W. Li, W. Qu, L. Wang, L. Li, Y. Li, F. Wu and R. Chen, Nano Energy, 2019, 60, 866-874.

74 Y. Zhong, X. Xu, W. Wang and Z. Shao, Batteries Supercaps, 2019, 2, 272-289.

75 Y. He, Y. Qiao, Z. Chang and H. Zhou, Energy Environ. Sci., 2019, 12, 2327-2344.

76 Y. Qiao, Y. He, S. Wu, K. Jiang, X. Li, S. Guo, P. He and H. Zhou, ACS Energy Lett., 2018, 3, 463-468.

77 Z. Wang, R. Tan, H. Wang, L. Yang, J. Hu, H. Chen and F. Pan, Adv. Mater., 2018, 30, 1704436.

78 P. M. Shanthi, P. J. Hanumantha, B. Gattu, M. Sweeney, M. K. Datta and P. N. Kumta, Electrochim. Acta, 2017, 229, 208-218.

79 M. Eddaoudi, J. Kim, N. Rosi, D. Vodak, J. Wachter, M. Keeffe and O. M. Yaghi, Science, 2002, 295, 469.

80 K. T. Lee, T. N. Ramesh, F. Nan, G. Botton and L. F. Nazar, Chem. Mater., 2011, 23, 3593-3600.

81 P. Simon and Y. Gogotsi, Nat. Mater., 2008, 7, 845-854.

82 T. D. Bennett, A. L. Goodwin, M. T. Dove, D. A. Keen, M. G. Tucker, E. R. Barney, A. K. Soper, E. G. Bithell, J.-C. Tan and A. K. Cheetham, Phys. Rev. Lett., 2010, 104, 115503.

83 C. D. Wessells, S. V. Peddada, R. A. Huggins and Y. Cui, Nano Lett., 2011, 11, 5421-5425. 
84 J. B. Goodenough and Y. Kim, Chem. Mater., 2010, 22, 587-603.

85 B. M. Wiers, M.-L. Foo, N. P. Balsara and J. R. Long, J. Am. Chem. Soc., 2011, 133, 14522-14525.

86 Y. An, H. Fei, Z. Zhang, L. Ci, S. Xiong and J. Feng, Chem. Commun., 2017, 53, 8360-8363.

87 D. Luo, P. Lei, G. Tian, Y. Huang, X. Ren and X. Xiang, J. Phys. Chem. C, 2020, 124, 5958-5965.

88 J. Park, M. Lee, D. Feng, Z. Huang, A. C. Hinckley, A. Yakovenko, X. Zou, Y. Cui and Z. Bao, J. Am. Chem. Soc., 2018, 140, 10315-10323.

89 C. Li, X. Hu and B. Hu, Electrochim. Acta, 2017, 253, 439-444.

90 M. V. Reddy, G. V. Subba Rao and B. V. R. Chowdari, Chem. Rev., 2013, 113, 5364-5457.

91 Y. Li, Y. Xu, W. Yang, W. Shen, H. Xue and H. Pang, Small, 2018, 14, 1704435.

92 X. Wu, M. Sun, S. Guo, J. Qian, Y. Liu, Y. Cao, X. Ai and H. Yang, ChemNanoMat, 2015, 1, 188-193.

93 C. D. Wessells, S. V. Peddada, M. T. McDowell, R. A. Huggins and Y. Cui, J. Electrochem. Soc., 2011, 159, A98-A103.

94 G. Fang, Q. Wang, J. Zhou, Y. Lei, Z. Chen, Z. Wang, A. Pan and S. Liang, ACS Nano, 2019, 13, 5635-5645.

95 Y. Lu, L. Wang, J. Cheng and J. B. Goodenough, Chem. Commun., 2012, 48, 6544-6546.

96 L. Wang, Y. Lu, J. Liu, M. Xu, J. Cheng, D. Zhang and J. B. Goodenough, Angew. Chem., Int. Ed., 2013, 52, 1964-1967.

97 X. Wang, R. Kurono, S.-I. Nishimura, M. Okubo and A. Yamada, Chem. - Eur. J., 2015, 21, 1096-1101.

98 G. Zou, J. Chen, Y. Zhang, C. Wang, Z. Huang, S. Li, H. Liao, J. Wang and X. Ji, J. Power Sources, 2016, 325, 25-34.

99 Z. Zhang, J. Feng, L. Ci, Y. Tian and S. Xiong, Mater. Technol., 2016, 31, 497-500.

100 M. Hu, J. Reboul, S. Furukawa, N. L. Torad, Q. Ji, P. Srinivasu, K. Ariga, S. Kitagawa and Y. Yamauchi, J. Am. Chem. Soc., 2012, 134, 2864-2867.

101 N. Ingersoll, Z. Karimi, D. Patel, R. Underwood and R. Warren, Electrochim. Acta, 2019, 297, 129-136.

102 X. Shi, Y. Chen, Y. Lai, K. Zhang, J. Li and Z. Zhang, Carbon, 2017, 123, 250-258.

103 P. Xiong, X. Zhao and Y. Xu, ChemSusChem, 2018, 11, 202-208.

104 X. Zhou, L. Chen, W. Zhang, J. Wang, Z. Liu, S. Zeng, R. Xu, Y. Wu, S. Ye, Y. Feng, X. Cheng, Z. Peng, X. Li and Y. Yu, Nano Lett., 2019, 19, 4965-4973.

105 X. Liu, F. Zou, K. Liu, Z. Qiang, C. J. Taubert, P. Ustriyana, B. D. Vogt and Y. Zhu, J. Mater. Chem. A, 2017, 5, 11781-11787.

106 X. Xu, J. Liu, J. Liu, L. Ouyang, R. Hu, H. Wang, L. Yang and M. Zhu, Adv. Funct. Mater., 2018, 28, 1707573.

107 Y. Wang, Q. Deng, W. Xue, Z. Jian, R. Zhao and J. Wang, J. Mater. Sci., 2018, 53, 6785-6795.

108 S. Dong, C. Li, X. Ge, Z. Li, X. Miao and L. Yin, ACS Nano, 2017, 11, 6474-6482.

109 Y. Von Lim, S. Huang, Y. Zhang, D. Kong, Y. Wang, L. Guo, J. Zhang, Y. Shi, T. P. Chen, L. K. Ang and H. Y. Yang, Energy Storage Mater., 2018, 15, 98-107.

110 W. Shuang, H. Huang, L. Kong, M. Zhong, A. Li, D. Wang, Y. Xu and X.-H. Bu, Nano Energy, 2019, 62, 154-163.
111 R. Zhang, A. M. Esposito, E. S. Thornburg, X. Chen, X. Zhang, M. A. Philip, A. Magana and A. A. Gewirth, ACS Appl. Mater. Interfaces, 2020, 12, 29285-29295.

112 Y.-M. Chen, W. Liang, S. Li, F. Zou, S. M. Bhaway, Z. Qiang, M. Gao, B. D. Vogt and Y. Zhu, J. Mater. Chem. A, 2016, 4, 12471-12478.

113 S. Wei, S. Xu, A. Agrawral, S. Choudhury, Y. Lu, Z. Tu, L. Ma and L. A. Archer, Nat. Commun., 2016, 7, 11722.

114 Y. Guo, H. Jin, Z. Qi, Z. Hu and H. Ji, Adv. Funct. Mater., 2019, 29, 1807676.

115 L. Kong, C. Yan, J.-Q. Huang, M.-Q. Zhao, M.-M. Titirici, R. Xiang and Q. Zhang, Energy Environ. Mater., 2018, 1, 100-112.

116 J. Wang, L. Si, Q. Wei, X. Hong, S. Cai and Y. Cai, ACS Appl. Nano Mater., 2018, 1, 132-138.

117 Z. Chang, Y. Qiao, J. Wang, H. Deng, P. He and H. Zhou, Energy Storage Mater., 2020, 25, 164-171.

118 A. Manthiram, Y. Fu, S.-H. Chung, C. Zu and Y.-S. Su, Chem. Rev., 2014, 114, 11751-11787.

119 B. Zhu, Z. Liang, D. Xia and R. Zou, Energy Storage Mater., 2019, 23, 757-771.

120 S. S. Shinde, C. H. Lee, J.-Y. Jung, N. K. Wagh, S.-H. Kim, D.-H. Kim, C. Lin, S. U. Lee and J.-H. Lee, Energy Environ. Sci., 2019, 12, 727-738.

121 T. Li, Y. Chen, Z. Tang, Z. Liu and C. Wang, Electrochim. Acta, 2019, 307, 403-413.

122 G. Chen, J. Zhang, F. Wang, L. Wang, Z. Liao, E. Zschech, K. Müllen and X. Feng, Chem. - Eur. J., 2018, 24, 18413-18418.

123 W. Xiong, H. Li, H. You, M. Cao and R. Cao, Natl. Sci. Rev., 2019, 201.

124 X. Wu, G. Meng, W. Liu, T. Li, Q. Yang, X. Sun and J. Liu, Nano Res., 2018, 11, 163-173.

125 Z. Li, W. Zhao, C. Yin, L. Wei, W. Wu, Z. Hu and M. Wu, ACS Appl. Mater. Interfaces, 2017, 9, 44519-44528.

126 Y. Liu, H. Jiang, J. Hao, Y. Liu, H. Shen, W. Li and J. Li, ACS Appl. Mater. Interfaces, 2017, 9, 31841-31852.

127 M. Abirami, S. M. Hwang, J. Yang, S. T. Senthilkumar, J. Kim, W.-S. Go, B. Senthilkumar, H.-K. Song and Y. Kim, ACS Appl. Mater. Interfaces, 2016, 8, 32778-32787.

128 S.-L. Li and Q. Xu, Energy Environ. Sci., 2013, 6, 1656-1683.

129 X. Li, F. Cheng, S. Zhang and J. Chen, J. Power Sources, 2006, 160, 542-547.

130 G. Férey, F. Millange, M. Morcrette, C. Serre, M. L. Doublet, J. M. Grenèche and J. M. Tarascon, Angew. Chem., Int. Ed., 2007, 46, 3259-3263.

131 G. De Combarieu, M. Morcrette, F. Millange, N. Guillou, J. Cabana, C. P. Grey, I. Margiolaki, G. Férey and J. M. Tarascon, Chem. Mater., 2009, 21, 1602-1611.

132 Z. Zhu, M. Hong, D. Guo, J. Shi, Z. Tao and J. Chen, J. Am. Chem. Soc., 2014, 136, 16461-16464.

133 Y. Hanyu, Y. Ganbe and I. Honma, J. Power Sources, 2013, 221, 186-190.

134 Y. Hanyu and I. Honma, Sci. Rep., 2012, 2, 453.

135 Y. Hanyu, T. Sugimoto, Y. Ganbe, A. Masuda and I. Honma, J. Electrochem. Soc., 2013, 161, A6. 
136 A. S. Hameed, M. V. Reddy, M. Nagarathinam, T. Runčevski, R. E. Dinnebier, S. Adams, B. V. R. Chowdari and J. J. Vittal, Sci. Rep., 2015, 5, 16270.

137 A. S. Hameed, M. V. Reddy, N. Sarkar, B. V. R. Chowdari and J. J. Vittal, RSC Adv., 2015, 5, 60630-60637.

138 A. S. Hameed, M. Nagarathinam, M. Schreyer, M. V. Reddy, B. V. R. Chowdari and J. J. Vittal, J. Mater. Chem. A, 2013, 1, 5721-5726.

139 A. Y. Maulana, C. M. Futalan and J. Kim, J. Alloys Compd., 2020, 840, 155719.

140 C. D. Wessells, R. A. Huggins and Y. Cui, Nat. Commun., 2011, 2, $1-5$.

141 W.-J. Li, S.-L. Chou, J.-Z. Wang, Y.-M. Kang, J.-L. Wang, Y. Liu, Q.-F. Gu, H.-K. Liu and S.-X. Dou, Chem. Mater., 2015, 27, 1997-2003.

142 Y. Liu, Y. Qiao, W. Zhang, Z. Li, X. Ji, L. Miao, L. Yuan, $\mathrm{X}$. Hu and Y. Huang, Nano Energy, 2015, 12, 386-393.

143 Y. You, X.-L. Wu, Y.-X. Yin and Y.-G. Guo, Energy Environ. Sci., 2014, 7, 1643-1647.
144 L. Li, P. Nie, Y. Chen and J. Wang, J. Mater. Chem. A, 2019, 7, 12134-12144.

145 L. Wang, J. Song, R. Qiao, L. A. Wray, M. A. Hossain, Y.D. Chuang, W. Yang, Y. Lu, D. Evans and J.-J. Lee, J. Am. Chem. Soc., 2015, 137, 2548-2554.

146 B. Xie, P. Zuo, L. Wang, J. Wang, H. Huo, M. He, J. Shu, H. Li, S. Lou and G. Yin, Nano Energy, 2019, 61, 201-210.

147 S. Li, H. Yang, R. Xu, Y. Jiang, Y. Gong, L. Gu and Y. Yu, Mater. Chem. Front., 2018, 2, 1574-1582.

148 B. He, Q. Zhang, P. Man, Z. Zhou, C. Li, Q. Li, L. Xie, X. Wang, H. Pang and Y. Yao, Nano Energy, 2019, 64, 103935.

149 F. Wu, X. Gao, X. Xu, Y. Jiang, R. Yin, W. Shi, W. Liu, G. Lu and X. Cao, ChemSusChem, 2020, 13, 1537-1545.

150 W. Shi, J. Mao, X. Xu, W. Liu, L. Zhang, X. Cao and X. Lu, J. Mater. Chem. A, 2019, 7, 15654-15661.

151 W. Liu, R. Yin, W. Shi, X. Xu, X. Shen, Q. Yin, L. Xu and X. Cao, ACS Appl. Energy Mater., 2019, 2, 579-586.

152 W. Shi, X. Liu, T. Deng, S. Huang, M. Ding, X. Miao, C. Zhu, Y. Zhu, W. Liu and F. Wu, Adv. Mater., 2020, 32, 1907404. 